\title{
Response of the Large-Scale Structure of the Atmosphere to Global Warming
}

\author{
Geoffrey K. Vallis*, Pablo Zurita-Gotor, Cameron Cairns and Joseph Kidston \\ University of Exeter, Universidad Complutense, Madrid, and University of New South Wales \\ *Correspondence to: Geoffrey K. Vallis, University of Exeter, g.vallis@exeter.ac.uk
}

This paper discusses the possible response of the large-scale atmospheric structure to a warmer climate. Using integrations from the fifth phase of the Coupled Model Intercomparison Project (CMIP5) in conjunction with physical arguments, we try to identify what changes are likely to be robust and what the underlying mechanisms might be. We focus on the large-scale zonally-averaged circulation, in particular on height of the tropopause, the strength and position of the surface westerlies and the strength and extent of the Hadley Cell. We present analytic arguments and numerical calculations that suggest that under global warming the height of the tropopause will increase in both the transient response and final equilibrium state, and an increase is clearly found in all the comprehensive models in CMIP5. Upper stratospheric cooling is also found in the comprehensive models, and this too can be explained by a radiative argument. Regarding the circulation, most models show a slight expansion and weakening of the Hadley Cell, depending on season and hemisphere. The expansion is small and largely confined to winter but with some expansion in Southern Hemisphere summer. The weakening occurs principally in Northern Hemisphere but the intermodel scatter is large. There is also a general polewards shift in surface westerlies, but the changes are small and again are little larger than the inter-model variability in the change. This shift is correlated with the Hadley Cell expansion but to a degree that depends on the metric chosen for the latter. There is a robust strengthening in the Southern Hemisphere surface winds across seasons. In the Northern Hemisphere there is a slight strengthening in the westerlies in most models in winter but a consistent weakening of the westerlies in summer. We present various physical arguments concerning these circulation changes but none that are both demonstrably correct and that account for the model results. We conclude that the above-mentioned large-scale thermodynamic/radiative changes in the large-scale atmospheric structure are generally robust, in the sense of being both well understood and consistently reproduced by comprehensive models. In that sense the dynamical changes are less robust given the current state of knowledge and simulation, although one cannot conclude that they are, in principle, unknowable or less predictable. 


\section{Introduction}

Over the past 200 years or so the level of greenhouse gases (GHGs) in the atmosphere has increased considerably - for example the $\mathrm{CO}_{2}$ level has increased from about $280 \mathrm{ppm}$ to $400 \mathrm{ppm}$ - and is likely to further increase in the decades ahead. It is almost certain that the globally averaged surface temperature, and indeed of the troposphere, has increased as a direct consequence of this and will continue to increase in the future. Measures of the increase in average surface temperature for a given increase in GHGs, and in particular for a doubling in $\mathrm{CO}_{2}$ level, are generically known as the climate sensitivity and considerable effort goes into trying to reduce the uncertainty in our estimates of these. Much of the uncertainty revolves around understanding the response of cloud systems and, in terms of the rate of approach to equilibrium, the heat uptake by the ocean.

But even if the climate sensitivity were known with little uncertainty, a problem arises in understanding the regional changes in climate, and that in turn involves the dynamical issue of understanding changes in the general circulation of the atmosphere. As a step toward that, our primary goal in this paper is to better understand what changes in large scale atmospheric structure are likely, or robust, as the planet warms. Our approach is two-fold. On the one hand, as an empirical tool we use the archive of coupled climate models used for the fifth assessment report (AR5) of the Intergovernmental Panel on Climate Change (IPCC) to assess the robustness of model responses to a given warming or given emissions scenario. In addition, we try to assess whether the response is consistent with or explainable by simple physical arguments, some of which have been presented in the literature before (see also the review by Schneider et al. 2010)). Our general point of view is that robustness is most assured if there is agreement across a range of comprehensive and idealized models and if there is a well understood physical argument that captures the phenomenon. We spend more time describing arguments that are clear and robust; thus we discuss the mechanism of an increase in tropopause height at some length but do not go into such detail regarding the various arguments for latitudinal shifts of the circulation.

The importance of the dynamical response can be appreciated by realizing that a latitudinal shift of just a couple of degrees in the mid-latitude baroclinic zone, or a small change in the extent of the Hadley Cell, could lead to relatively large changes in the climates at the edge of these regions, potentially larger than the average change in overall climate. Thus, without

(C) 0000 Royal Meteorological Society a better understanding of changes in the general circulation, even if the uncertainty in globally-averaged quantities could be made small, the societally-relevant problem of predicting regional climate change would remain.

The general circulation is a large topic and to keep the article manageable we focus on just a few topics and perforce neglect others. Our goal is to provide a basis for considering the problem as a whole, rather than to examine a particular topic in detail. Thus, our focus is on the large-scale structure of the atmosphere and how it might change in the zonal mean, without consideration of longitude. We perforce omit some important topics, perhaps most egregiously the discussion of the intensity or longitudinal structure of storm tracks and the whole topic of changes in climate variability. Similarly, we discuss the hydrology cycle only in a perfunctory way, we do not discuss climate extremes, and do we not discuss smaller scale phenomena such as hurricanes or monsoons. In short, we take a global view in style and content.

The paper is organized as follows. In section 2 we introduce the IPCC/CMIP5 simulations and present some basic results regarding temperature trends. In section 3 we discuss the factors leading to an increase in height of the tropopause and the cooling of the stratosphere, and we present some radiative calculations as well as various results from CMIP5 simulations. In section 4 we discuss the midlatitude circulation, focussing on the latitude and strength of the surface westerlies. In section 5 we similarly consider the expansion of the Hadley Cell from both a theoretical and modelling perspective, and finally, in section 6 , we provide some summary remarks.

\section{IPCC Model Simulations}

The comprehensive model simulations we use are taken from the IPCC AR5 archive, and in particular from those submitted to the fifth phase of the Coupled Model Intercomparison Project (CMIP5). We have evaluated the response of the atmosphere for two scenarios - one with a $1 \%$ a year $\mathrm{CO}_{2}$ increase (denoted the ' $1 \%$ ensemble') and the RCP8.5 scenario (Meinshausen et al. 2011) - with each ensemble having about 30 member (see tables 1 and 2). The former is very clean in that the forcing for each model is very well defined with carbon dioxide increasing at a uniform rate and with no complicating factors from changes in other absorbers or ozone. The RCP8.5 scenario has relatively large increases in GHGs, with an additional radiative forcing of about $8.5 \mathrm{~W} \mathrm{~m}^{-2}$ by year 2100 and so relatively large responses. If the response 
(a)

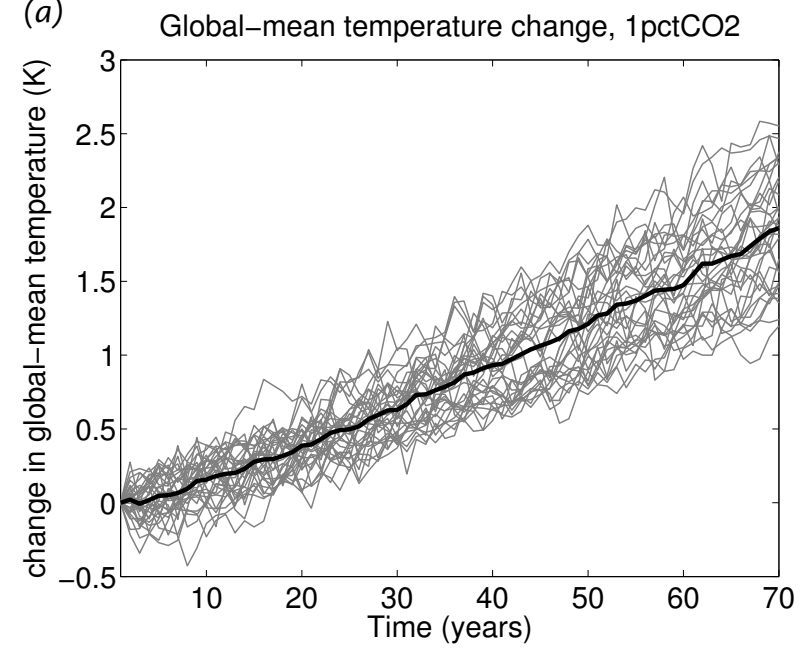

(b) Global-mean temperature change, rcp8.5

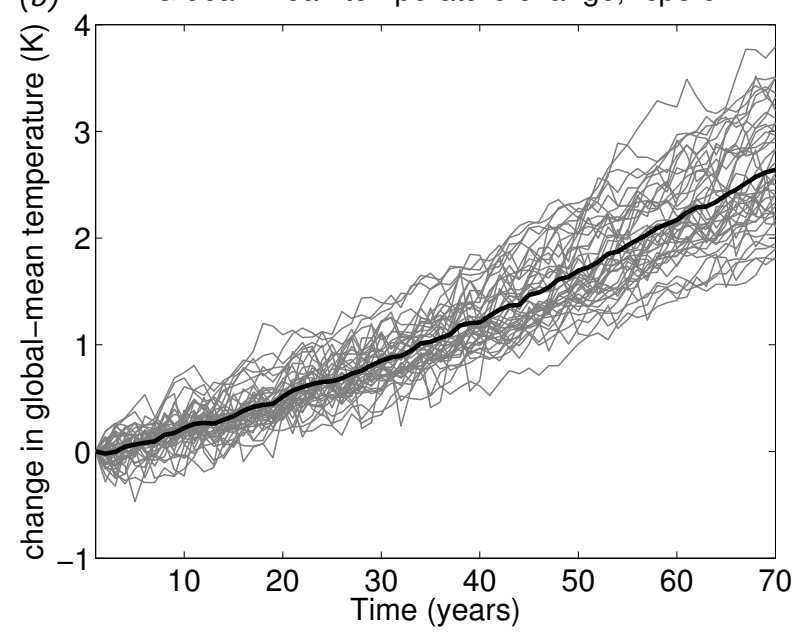

Figure 1. (a) Time series of the change in global mean temperature during the $1 \%$ integrations for individual models (thin grey lines lines) and the ensemble mean (thicker black line). (b) The same as (a) but for the RCP8.5 scenario.

is generally clear and more-or-less the same between scenarios we present results from just one, usually the $1 \%$ scenario, and indeed by and large our results and interpretations do not differ significantly between scenarios. In some cases, usually when the results are surprising or ambiguous, or particularly basic, we will present results from both scenarios. We do not look at the causes of differences between individual models, and so do not identify the models that produce specific results although the determined reader may be able to deduce this information using the tables. Our focus is not on the quantitative increases in temperature and related fields that might actually occur over the coming decades; rather, we are interested in how the large-scale structure of the atmosphere might respond to such changes. In most cases we show a trended difference between year 1 and year 70, this interval corresponding to a doubling of $\mathrm{CO}_{2}$ levels in the $1 \%$ ensemble. The difference is calculated by least-squares fitting a linear trend to the field or value in question and using the difference in the values of the fit at the start of the integration and at year 70 , so minimizing the effects of natural variability,

\subsection{Preliminaries}

We first present a few results regarding the changes in temperature and precipitation in the model scenarios. Figure 1 shows the time series of the change in global mean surface temperature over the next 70 years for two scenarios. From panel (a) we see that the mean transient climate response (TCR) in the $1 \%$ scenario is about $1.8 \mathrm{~K}$, with individual model results nearly all in the range of $1.3 \mathrm{~K}$ to $2.5 \mathrm{~K}$. The responses of the models in the RCP8.5 scenario are higher, with an average of

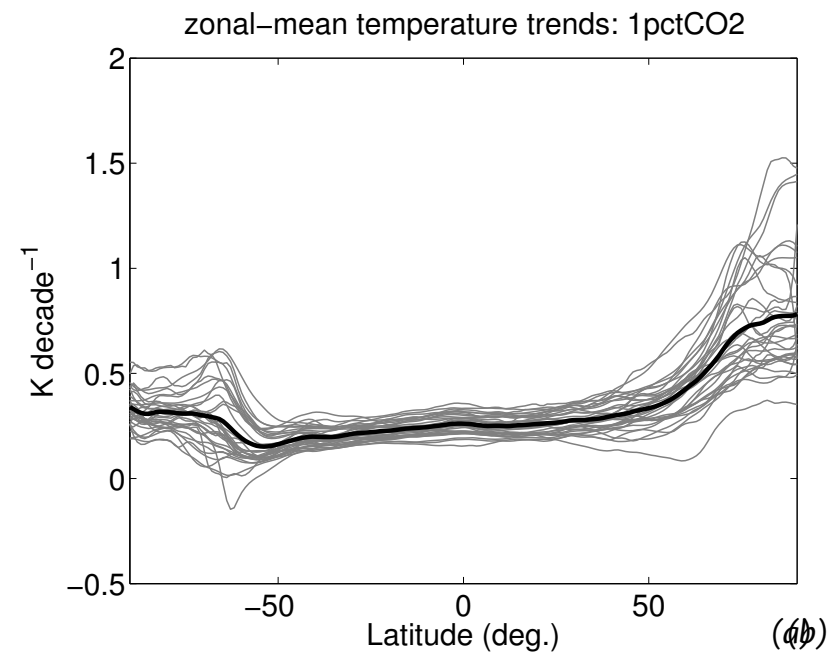

Figure 2. (a) The zonal-mean surface temperature trend from year 1 to year 70 in the $1 \%$ ensemble. The thin grey lines are for individual models and the thicker black line is the ensemble mean, and the ordinate is degrees per decade. The RCP8.5 results have a very similar pattern.

about $2.6 \mathrm{~K}$ and most in the range of $1.9 \mathrm{~K}$ to $3.4 \mathrm{~K}$ consistent with higher emissions.

Figure 2 shows the zonal mean surface temperature trend from year 1 to year 70 , and we see surface polar amplification in the Northern Hemisphere in nearly all models (also look ahead to Fig. 6). This familiar effect is usually attributed it to an increase of surface albedo associated with a retreat of seaice and snow, amplified and extended by a low level thermal inversion that reduces the loss of longwave radiation to space (e.g. Winton 2006; Screen and Simmonds 2010; Bintanja et al. 2011). The spatial pattern of temperature increase is shown in Fig. 3, 


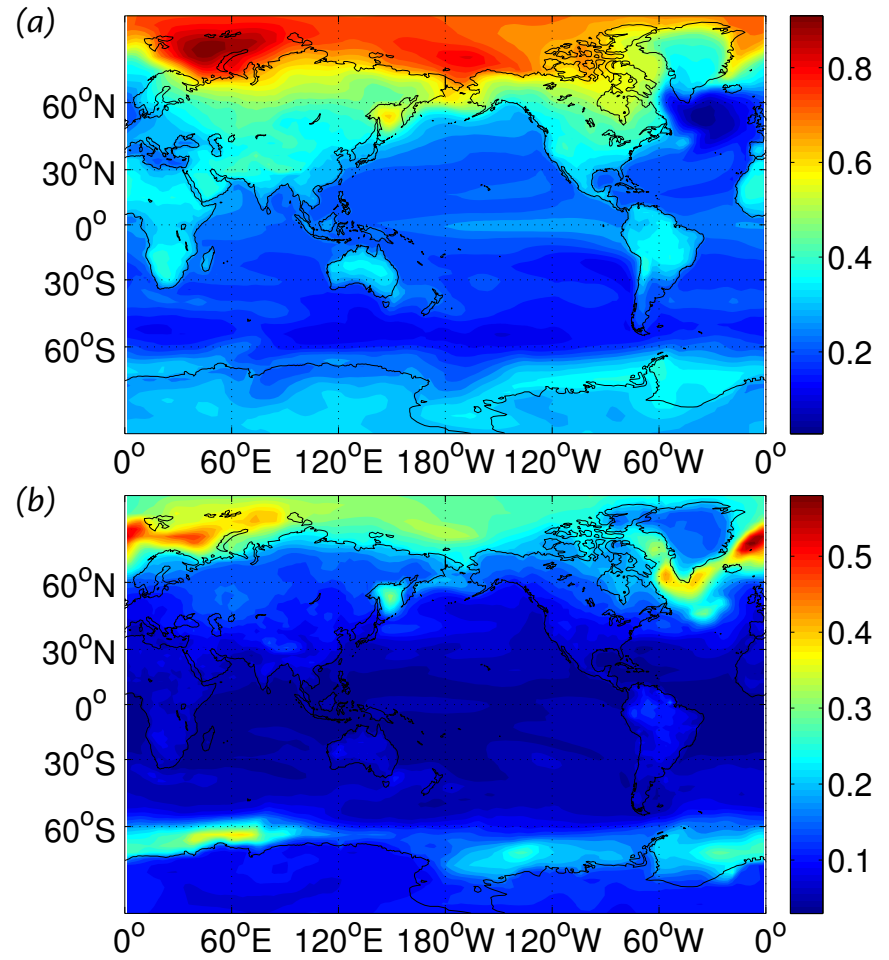

Figure 3. (a) The ensemble-mean surface temperature trend (degrees per decade) in the $1 \%$ integrations (annual mean). (b) The inter-model standard-deviation of the trend. Note difference in scale.

which shows the ensemble mean surface temperature trend (in degrees per decade) from the $1 \%$ integrations as a function of latitude and longitude. That land warms more readily than the oceans is clearly seen, as previously noted and discussed by Sutton et al. (2007); Joshi et al. (2008); Kamae et al. (2014) and others. Also, over most of the globe, the temperature trend itself is notably larger than the inter-model standard deviation of the trend, which may be regarded as a measure of robustness. The standard deviation of the trend is largest at high latitudes where the response of the sea ice varies between models (although that does not imply a causal relationship).

Trends of zonally-averaged precipitation are illustrated in Fig. 4. The precipitation trend has a distinctive pattern similar to that of the precipitation itself and, although there is some scatter among the various models (Fig. 4b) the pattern is fairly robust (consistent with Knutti and Sedlacek 2012). It is interesting that the distinctive pattern of the precipitation changes comes almost entirely from the response over ocean, as can be seen from Fig. 5 (Held and Soden (2006) and Chou et al. (2009) give discussion of the 'wet gets wetter' argument). A simple point to be made here is that this difference over land and water is indicative of the importance of changes in the circulation.
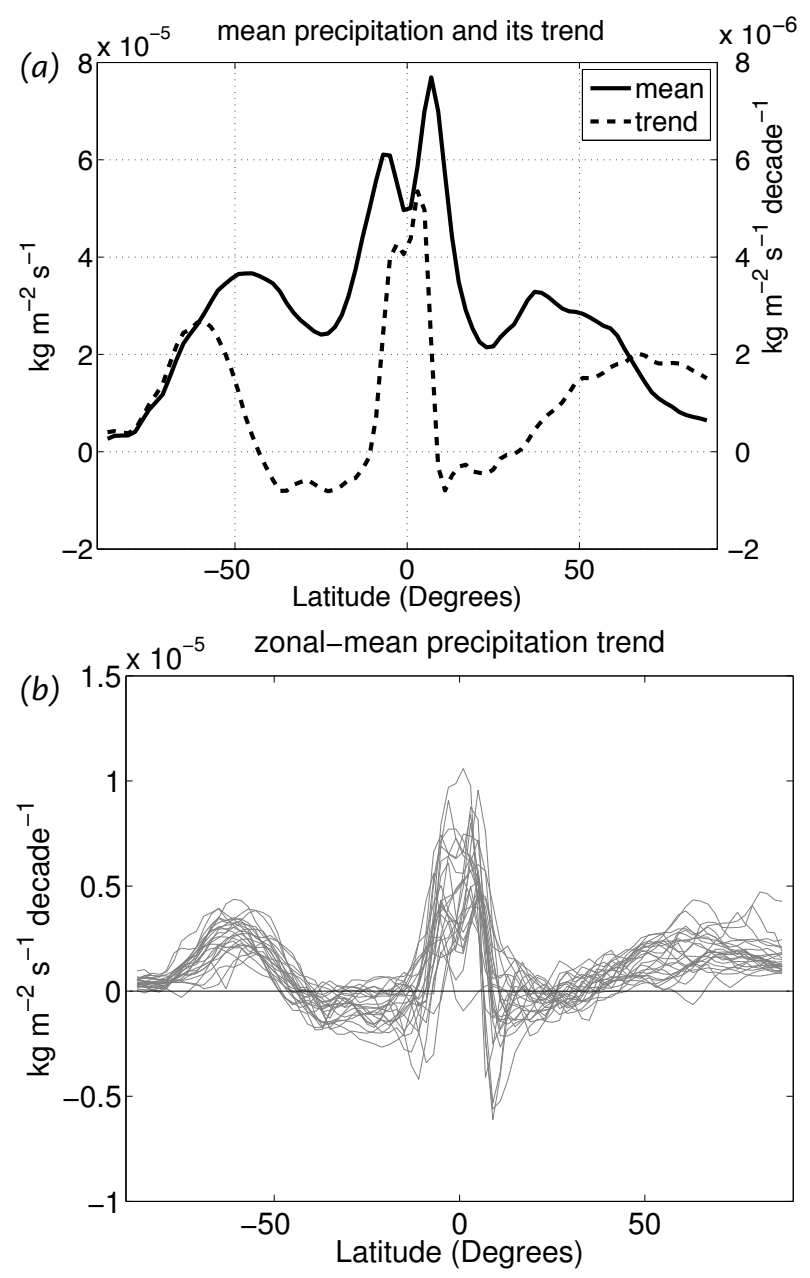

Figure 4. (a) The time-mean zonal-mean ensemble-mean precipitation (solid line), and the zonal-mean ensemble-mean trend (dashed line), for the $1 \%$ ensemble. (b) Trends from individual models. Note the two ordinates in (a).

Turning our attention to the structure of the atmosphere, Fig. 6 shows the temperature trends (degrees per decade) for an ensemble of models from the $1 \%$ scenario. We also plot the ensemble-average position of the tropopause (using the WMO definition) at year 1 and year 70 . In addition to the overall warming of the troposphere the following features stand out: (i) An enhanced warming aloft in the tropics; (ii) a surface polar amplification in the Northern Hemisphere, as noted earlier; (iii) an increase in height of the tropopause; (iv) upper stratospheric cooling; (v) from the position of the tropopause there is also a hint of tropical expansion. A number of these features have been noted in previous numerical simulations and in some cases in observations. Thus, the enhanced tropical warming aloft result goes back at least to Manabe and Wetherald (1980) with consistent results since from a variety of models (Meehl et al. 2007) and observations (Santer et al. 2008). This warming 

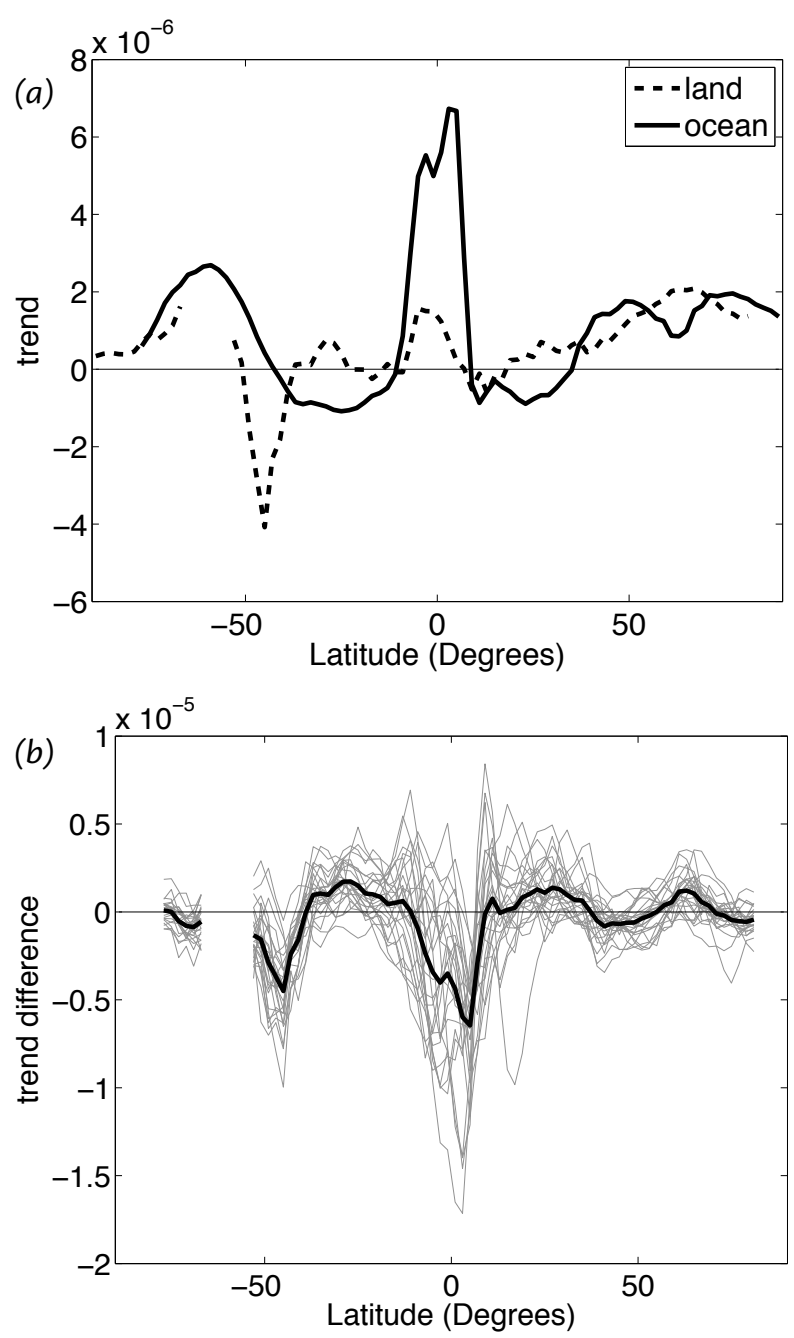

Figure 5. (a) The zonal-mean ensemble-mean precipitation trend over land only (dashed) and ocean only (solid) for the $1 \%$ integrations. (b) The difference in the zonal-mean trend over land and over the ocean for individual models (grey lines) and the ensemble-mean (black). Units as in Fig. 4.

can be attributed to a decrease in the saturated lapse rate with increased water vapour content following warming - an increase in temperature of $1 \mathrm{~K}$ leads, rather approximately, to a decrease in lapse rate of about $0.1 \mathrm{~K} \mathrm{~km}^{-1}$, so that a warming at the surface of $1 \mathrm{~K}$ gives double that warming at $10 \mathrm{~km}$. Although it is only in convective regions where the moist adiabatic lapse rate directly controls the temperature aloft, horizontal temperature gradients tend to be small at low latitudes (Sobel et al. 2001) and the warming spreads throughout the tropics. We will discuss the other effects in more detail in the sections below.

\section{The Height of the Tropopause and the Cooling of the Stratosphere}

The increase in tropopause height for each model is shown in Fig. 7. Nearly every model shows an increase in height at all latitudes, and the change in the mean height is significantly larger than the standard deviation of the inter-model change at all latitudes (Fig. $7 \mathrm{~b}$ ), suggesting that the change is robust. Indeed in the global mean the ratio of the change in mean height to the standard deviation of the change is 4.5 . The increase in tropopause height is noticeably larger in the tropics than in mid-latitudes, although at very high latitudes and notably in the Southern Hemisphere there is a still larger increase. An observed increase in the height of the tropopause was noted and attributed to anthropogenic forcing by Santer et al. (2003) and Kang et al. (2013) found it to be a robust result in a modelling study. Using a straightforward radiative calculation we will show that it is an expected and robust result of increased greenhouse gases, and that the larger increase in the tropics is also to be expected. We will then give a related argument showing that stratospheric cooling is also an expected and robust result, although in this case the result will be found to depend on the presence of a stratospheric source of diabatic heating such as ozone.

\subsection{Cause of the increase of tropopause height}

Consider a troposphere in which the temperature falls with height, and suppose that there is a radiatively thin stratosphere above it. With the addition of greenhouse gases the effective emitting level (i.e., the level at which the outgoing longwave radiation is equal to upwelling longwave emission at that level) in the troposphere increases, but in equilibrium the topof-the-atmosphere outgoing longwave radiation (OLR) is constrained, on average, to be equal to the net incoming solar radiation (i.e., the net downward topof-the-atmosphere shortwave radiation) and therefore the OLR does not change (at least in equilibrium; we discuss the modifications due to transience later). Hence the emitting temperature stays the same, and if the stratification of the column does not change then height of the effective emitting level must increase and the column will warm. The amount by which the emitting level increases depends on the change in the infra-red opacity of the atmosphere and is not amenable to anything but a detailed calculation. Nevertheless, without doing such a detailed calculation, a recasting of an argument of Thuburn and Craig (2000) suggests that the tropopause will increase in height by an amount similar to the increase in the emitting height. The assumptions are that the atmosphere is grey, that the troposphere has a constant lapse rate $\Gamma$ up to a tropopause, that the stratosphere above is in radiative equilibrium, and that outgoing longwave radiation 

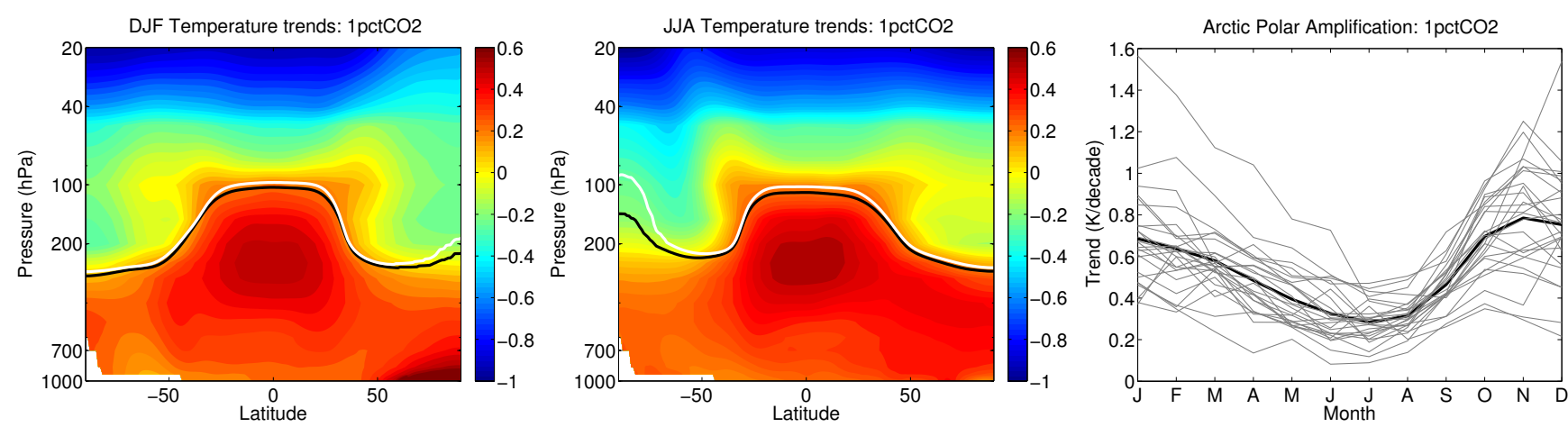

Figure 6. The ensemble-mean zonal-mean temperature trend (degrees per decade) from the $1 \%$ ensemble, for DJF and JJA, as labelled. The thin black and white lines mark the ensemble-average tropopause position, using the WMO definition, at year 1 and year 70. The rightmost panel shows the annual cycle of the temperature trend for the ensemble average (thick line) and individual models (thin lines), over a volume extending from the surface to $925 \mathrm{hPa}$ and from $60^{\circ} \mathrm{N}$ to $90^{\circ} \mathrm{N}$.

stays approximately fixed. We discuss the limitations of these assumptions later.

In a grey atmosphere with $\tau$ decreasing upwards, the upwards, $U$, and downwards, $D$, infra-red irradiance are governed by the radiative transfer equations (Goody 1964)

$$
\frac{\partial U}{\partial \tau}=U-B, \quad \frac{\partial D}{\partial \tau}=B-D
$$

where $B=\sigma T^{4}$, with $\sigma=5.67 \times 10^{-8} \mathrm{~W} \mathrm{~m}^{-2}$ being the Stefan-Boltzmann constant, and $\tau(z)$ is the optical depth. A factor of $3 / 2$ is sometimes included in these equations but we include that in the definition of optical depth. The equations may also be written as

$$
\begin{array}{r}
\frac{\partial}{\partial \tau}(U-D)=U+D-2 B, \\
\frac{\partial}{\partial \tau}(U+D)=U-D
\end{array}
$$

This form is useful because the net infrared flux is $I=U-D$ and the longwave heating is proportional its vertical divergence, $\partial I / \partial z$, and thus related to $\partial I / \partial \tau$. At the 'top' of the atmosphere, namely where $\tau=0$, we must have $U=O L R$ and $D=0$, where $O L R$ is the outgoing longwave radiation. Averaged over the planet, and presuming that the planet as a whole is in radiative balance, then $O L R=S_{0}=$ constant, where $S_{0}$ is the net incoming solar radiation.

A simple model of the vertical structure of the atmosphere supposes that the troposphere is that region in which the lapse rate is determined by fast dynamical process, such as convection and transport by baroclinic instabilities, whereas in the stratosphere the dynamical processes are slow and radiative equilibrium approximately holds. If we consider first the case in which the stratosphere is in a longwave radiative equilibrium then $\partial I / \partial \tau=0$ and hence $I=$
$O L R$ is constant in the stratosphere and, from (3.2a), $B=(U+D) / 2$. We can then straightforwardly integrate (3.2) and obtain

$$
\begin{gathered}
D=\frac{\tau}{2} \text { OLR, } \quad U=\left(1+\frac{\tau}{2}\right) O L R, \\
B=\frac{1+\tau}{2} O L R .
\end{gathered}
$$

Let us now suppose that the stratosphere and upper troposphere are optically thin, with $\tau \ll 1$. In the stratosphere we have

$$
\begin{gathered}
D=0, \quad U=O L R, \\
B=O L R / 2 .
\end{gathered}
$$

Thus, in this approximation the stratosphere is isothermal and the upward and downward irradiances within it are constant. Furthermore, that temperature is a function only of the outgoing longwave radiation, which in equilibrium is equal to the net incoming solar radiation and which therefore does not change with increased greenhouse gases. Let us also suppose that the troposphere has a constant lapse rate $\Gamma$ up to the tropopause height $H_{T}$ so that

$$
\begin{aligned}
& T=T_{s}-\Gamma z, \quad z \leq H_{t} \\
& T=T_{s}-\Gamma H_{T}=\text { constant, } \quad z \geq H_{T} .
\end{aligned}
$$

where $T_{s}$ is the surface temperature. If we consider the tropopause to be the lowest point of the stratosphere, and noting that in radiative balance OLR is fixed independently of the optical depth, the temperature of the tropopause must also be fixed even as we change optical depth by adding greenhouse gases. (Note that, if $T_{T}$ is the tropopause temperature and if $T_{\mathrm{emit}}$ is the 'emitting temperature' such that $\sigma T_{\text {emit }}^{4}=O L R$, then from (3.4) we see that $T_{T}=2^{-1 / 4} T_{\text {emit }}$. Since $T_{\text {emit }}$ is unaltered with global warming, so is $T_{T}$.) Thus, given 
(a) zonal-mean tropopause height trends: 1 pctCO2

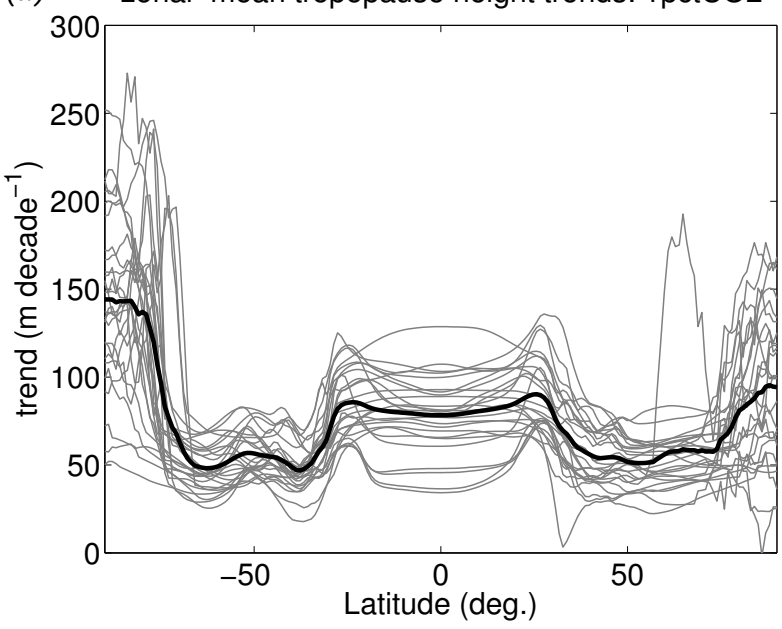

(b) (b) 1 pctCO2

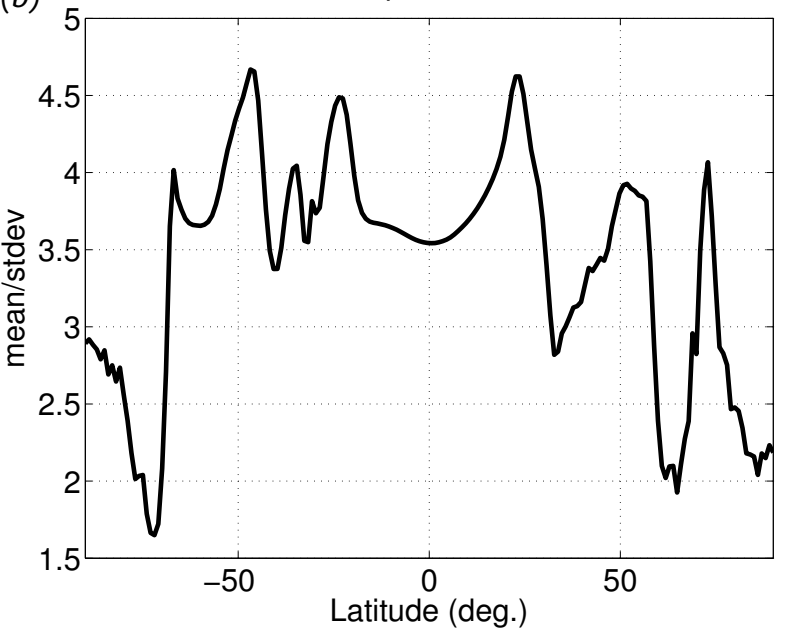

Figure 7. (a) The change in tropopause height as a function of latitude for individual models (grey) and the ensemble mean (black) in the 1PCT integrations. (b) Ratio of mean tropopause pressure change to the standard deviation of the change, as a function of latitude.

that temperature falls with height in the troposphere and that as we add greenhouse gases the temperature of the surface (and the troposphere) increases, the height of the tropopause will increase by an amount given by, if the changes are small,

$$
\Delta H_{T}=\frac{\Delta T}{\Gamma}-\frac{T_{s}-T_{T}}{\Gamma^{2}} \Delta \Gamma=\frac{\Delta T}{\Gamma}-\frac{H_{T} \Delta \Gamma}{\Gamma}
$$

where $\Delta T$ is the increase in surface temperature and $\Delta \Gamma$ is the change in the lapse rate. Alternatively,

$$
\frac{\partial H_{T}}{\partial T_{S}}=\frac{1}{\Gamma}-\frac{H_{T}}{\Gamma} \frac{\partial \Gamma}{\partial T_{\mathcal{S}}} .
$$

The first term on the right-hand side is the direct temperature effect and the second term is the lapserate effect, and if the lapse rate is moist adiabatic then the expression may be evaluated analytically (at a given pressure). The expression cannot, by itself, be used to determine the height of the tropopause because the constant of integration is not known. (Equation (3.5b) will give the tropopause height if $T_{s}$ and $\Gamma$ are known, although to calculate $T_{s}$ we still need to perform a radiative calculation.)

The two aforementioned effects have the same sign and over a range of temperatures they are comparable and substantial (in regions where lapse rate changes are predominantly due to changes in the moist adiabat). Thus, for example, for an increase in tropospheric temperature of $1 \mathrm{~K}$ and a fixed lapse rate of $5 \mathrm{~K} / \mathrm{km}$, the temperature effect will lead to an increase in tropopause height of $200 \mathrm{~m}$. Similarly, a $1 \mathrm{~K}$ increase in temperature will change the moist adiabatic lapse rate by about $0.11 \mathrm{~K} / \mathrm{km}$ at $280 \mathrm{~K}$ in the lower atmosphere, and if the tropopause height is initially $10 \mathrm{~km}$ then the lapse rate effect will cause it to rise by about $220 \mathrm{~m}$. The two effects are plotted in Fig. 8. The contour plot shows the changes in tropopause height, evaluated using (3.6), for specified changes in temperature and lapse rate, with a base lapse rate of $6 \mathrm{~K} \mathrm{~km}^{-1}$ and a base tropopause height of $10 \mathrm{~km}$, and assuming changes in lapse rate are not a function of height. The line plot evaluates the two terms on the right-hand side of (3.7) as a function of temperature. At low and high temperatures the lapse-rate effect is small because the change of moist adiabatic lapse rate with temperature becomes small. (At low temperatures it asymptotes to the dry adiabatic lapse rate, which is constant. At temperatures above $300 \mathrm{~K}$ the moist term in the numerator of the expression of the moist adiabatic lapse rate becomes substantial and acts to increase the lapse rate; the moist term in denominator is also increasing and the net effect is that changes in the lapse rate with temperature are small.)

The lapse-rate effect will be dominant in the tropics, since in mid-latitudes processes such as baroclinic instability also play a role in determining the lapse rate and, furthermore, in low latitudes the tropopause itself is higher. This argument suggests that the increase in tropopause height will be greater in the tropics. At high latitudes the lapse rate itself is small, which will also lead to a large increase in tropopause height, as is seen in Fig. 7, but we have not quantitatively checked the prediction. The results of a numerical calculation illustrating the radiative effect are shown in Fig. 9, showing an unambiguous increase in tropopause height. (We discuss the figure more in the subsection below.) 
(a)

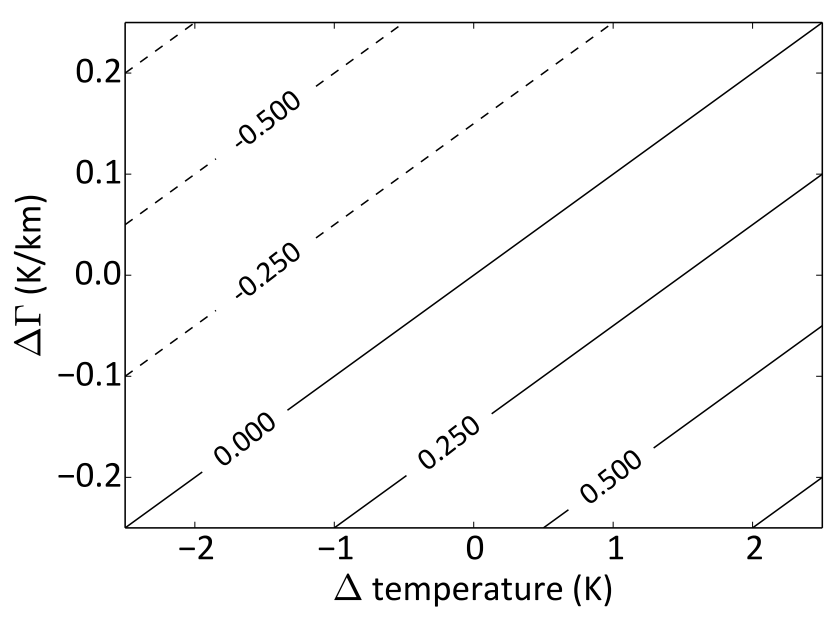

(b)

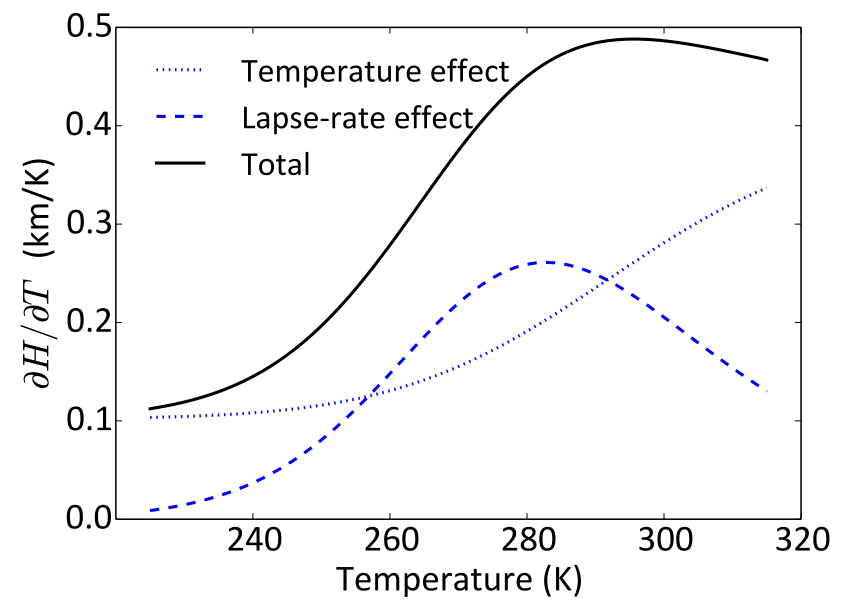

Figure 8. (a) Contours of change in tropopause height $(\mathrm{km})$ as a function of temperature change and lapse rate change, calculated using (3.6). (b) Rate of change of tropopause height with temperature $(\partial H / \partial T)$ as a function of temperature, calculated using (3.7) and the moist adiabatic lapse rate.

We now note the strengths and weaknesses of this argument. First of all, it is both simple and physically appealing, and does not depend on detailed radiative models. We have assumed that the atmosphere is grey but more complete radiative transfer equations have a similar form to those above and the essence of the argument, the increased emission with increased temperature, is robust aspect of radiation. Numerical calculations with broadband codes give qualitatively and even quantitatively similar results in appropriate comparisons (in particular Thuburn and Craig 2000 noted that sensitivity of tropopause height to lapse rate and temperature was very similar in broadband and grey models). Further, the nature of the result does not depend on the lapse rate being constant with height, or unchanging as the climate warms. The argument also gives a definite prediction for the increase in height of the tropopause. On the other hand, the requirement that the $O L R$ balance the net incoming solar radiation is a global one - it does not apply locally. Nonetheless, such a 'radiative constraint' is one ingredient in determining the tropopause height even in the presence of horizontal heat transport (Held 1982). If the horizontal transport of heat into a column is known, then the radiative constraint can be used to calculate the height of the tropopause if the tropospheric lapse rate is known. Thus, although the argument presented above does not apply locally, if the circulation does not significantly change then the convergence of heat into a column will also not significantly change.

Those changes in circulation that might affect the tropopause height include changes in the Brewer-Dobson circulation in the stratosphere and dynamically-forced changes in the tropospheric circulation (Zurita-Gotor and Vallis 2011), but these seem unlikely to be large enough negate the radiative effect. A $200 \mathrm{~m}$ change in tropopause height, with other factors staying constant, changes the radiative

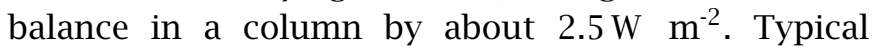
values of the divergence of energy flux are about $30 \mathrm{~W} \mathrm{~m}^{-2}$ (Peixoto and Oort 1992), so evidently these would need to change by about $10 \%$ to compensate for the radiative effects. Such a change would normally considered to be very large although it conceivably could occur at the edge of the tropics if the Hadley Cell width were to change, and Caballero and Langen (2005) also note that important changes in energy convergence with small circulation changes could arises because of changes in humidity. Changes in column energy balance could also have an effect on stratospheric temperature and and tropopause height because the of the smallness of optical depth in those regions. Notwithstanding all these caveats, the consistency of the CMIP5 results suggests that the radiative mechanism that we described above is the dominant one.

Finally, the quantitative result (3.7) does rely on the assumption that the outgoing longwave radiation does not appreciably change, which it could on two counts. One is that global warming could give rise to a change in albedo, whence the net incoming solar radiation would change, an eventuality can really only be accounted for in comprehensive models (if then). Second, Earth's atmosphere is only in radiative balance when in true equilibrium, and this may take hundreds of years or more to achieve after the initial increase in 
greenhouse gases, and we now discuss how this affects the above arguments.

\section{Transient vs equilibrium response}

In the transient state, before the planet has reached an overall radiative equilibrium, the outgoing longwave radiation will be less than the net incoming solar because there is a flux of energy into the ocean. But the atmosphere itself will be close to being in an energetic balance even in the transient state (because its heat capacity is relatively low) so that the outgoing longwave radiation will be less that the equilibrium value by an amount equal to the flux into the ocean, and within observational error this is found to be the case with both fluxes being of order $0.5 \mathrm{~W} \mathrm{~m}^{-2}$ (Loeb et al. 2012; Stephens et al. 2012). (The value of this flux is not deducible from a radiative calculation as it depends on ocean dynamics.)

The radiative-convective balance of the atmosphere in the transient state, then, is much more similar to that of the final state than to that of the initial state, except for some additional warming and associated further increase in the optical thickness of the atmosphere. It is true that the outgoing longwave radiation is less, but this is balanced by a small net flux of heat into the ocean. There is also a small difference in absolute temperature, but this has a negligible effect (see appendix). We therefore expect that the tropopause height will increase in the transient state to almost exactly the same height as in the final state, except for the effect of any further increases the optical depth. We demonstrate this with a numerical calculation. The numerical calculation solves the radiative transfer equations (3.1) assuming that there is a specified lapse rate $\Gamma$ up to a height $H_{T}$, and radiative equilibrium above. The optical depth is assumed to decay exponentially with height with an efolding scale of about $2 \mathrm{~km}$ and with a surface value of $8 / 3$. The boundary conditions are a specified outgoing radiation at the top of the atmosphere and zero downwelling radiation, and tropopause height is iterated until radiative balance is achieved. This procedure gives the 'initial' state in Fig. 9. The 'final' state is achieved by increasing the optical depth but keeping the same outgoing radiation, and we see that the solution produces a tropopause that is higher but that has almost exactly the same temperature. The 'transient' state has the same optical depth as the final state but has the outgoing radiation reduced (here by an unrealistically large $5 \mathrm{~W} \mathrm{~m}^{-2}$, to demonstrate the effect), corresponding to the flux into the ocean. The tropopause temperature is now lower than either the initial or final states, but its height is almost the same

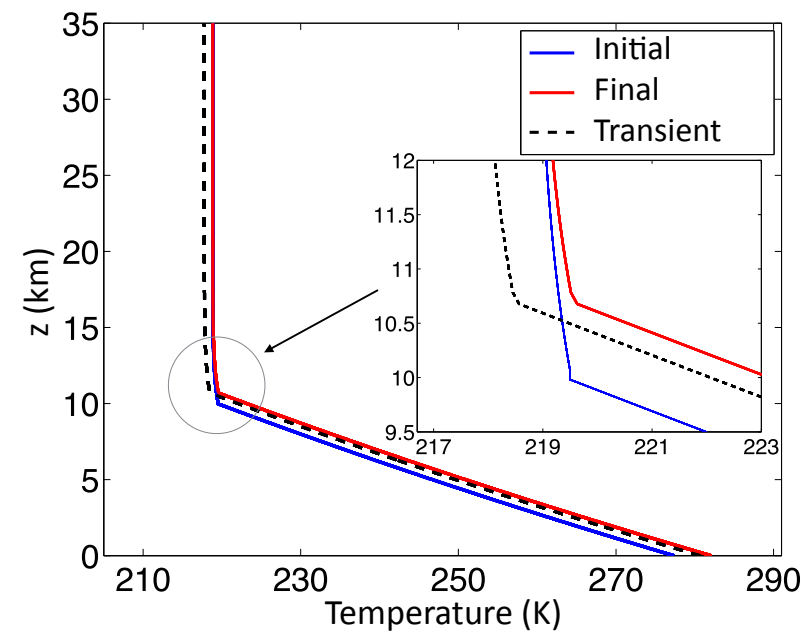

Figure 9. Initial, transient and final temperature profiles calculated numerically. The initial and final states have the same outgoing longwave radiation, and the same tropopause temperature. The transient state has a reduced outgoing longwave radiation but almost exactly the same tropopause height as the final state.

as that of the final state. Further discussion of this is given in the Appendix.

Thus, we conclude by noting that although (3.7) is unlikely to be locally quantitatively accurate, in the absence of unforseen feedbacks an increase in tropopause height with global warming is an almost inevitable consequence of straightforward radiative effects. Furthermore, models that have a higher climate sensitivity are likely to have a greater increase in tropopause height for a given increase in greenhouse gases.

\section{Tropopause height and climate sensitivity}

The arguments above suggest that the change in tropopause height should be correlated with the overall increase in temperature, and Fig. 10a shows that there is in fact a very good positive correlation between average increase in tropospheric height and TCR. The trend is about $300 \mathrm{~m}$ per degree, broadly consistent with the above estimates (see Fig. 8). There is also a fairly good correlation between TCR and changes in tropopause height at each latitude, as shown in Fig. 10b, with some tailing off at high latitudes. (The corresponding two plots for RCP8.5, not shown, are quite similar with some detailed differences in correlation at high latitudes.)

\subsection{The cooling of the stratosphere}

Stratospheric cooling as a response to increased greenhouse gases has been found in models going back at least to Manabe and Wetherald (1967), and Shine 
(a)

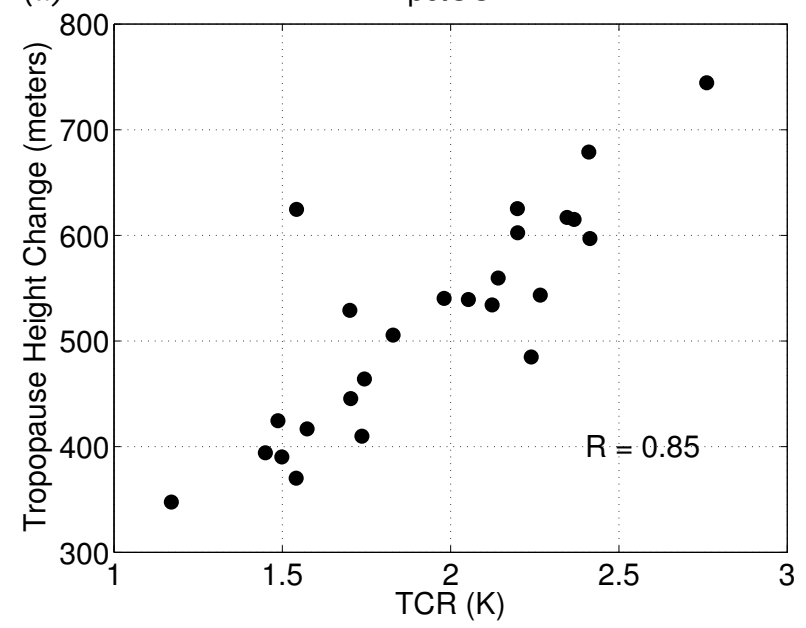

(b)

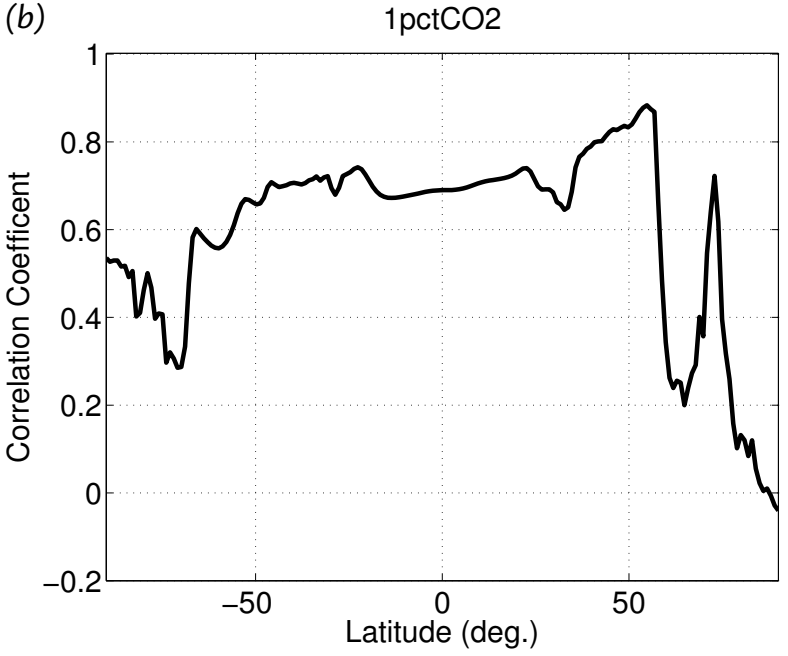

Figure 10. (a) Scatter plot of global-mean tropopause height change vs TCR for the $1 \%$ ensemble. (b) Correlation coefficient of TCR and tropopause height change as a function of latitude.

et al. (2003) note that there is strong evidence that the stratosphere has in fact cooled over recent decades. The reason for the cooling is not quite as simple as that sometimes given - in particular, it is wrong to say the change in temperature somehow 'pivots' around the effective emitting height, with warming beneath it and cooling above. On the other hand, nor does the explanation require a very detailed radiative calculation - in a grey atmosphere the cooling can be demonstrated with an analytic calculation, as follows. Consider the grey radiation model of (3.1) with an absorber that has an exponential profile

$$
\tau(z)=\tau_{0} \mathrm{e}^{-z / H_{a}}
$$

where $H_{a}$ is the absorber scale height. Typical values are $\tau_{0} \approx 4.0$ and $H_{a} \approx 2 \mathrm{~km}$ in the troposphere (assuming water vapour is the dominant greenhouse gas), although in the stratosphere and in a dryer atmosphere the assumption of a single rate of exponential decay is not a particularly good one. For simplicity we will suppose that as greenhouse gases are added then $\tau_{0}$ increases but $H_{a}$ remains the same.

Consider first the case in which stratosphere is in long-wave radiative equilibrium. Equations (3.3c) and (3.8) give

$$
\frac{\partial B}{\partial z}=-\frac{T}{2 H_{a}} O L R
$$

That is, temperature falls slightly with height, becoming isothermal as $\tau \rightarrow 0$. Now, if OLR stays the same then from $(3.3 c) B(\tau)$ is unaltered, with changes in $B(z)$, and hence $T(z)$ arising from the change in the mapping of $\tau$ to $z$. Thus,

$$
B(z)=\frac{1+\tau(z)}{2} O L R=\frac{1+\tau_{0} \mathrm{e}^{-z / H_{a}}}{2} O L R
$$

If $\tau_{0}$ increases then $B(z)$, and thus $T(z)$, will also increase. However, this increase will be very small because in the stratosphere the optical depth is small ( $\tau \ll 1)$. Thus, assuming that the stratosphere is in longwave radiative equilibrium leads to changes in temperature with increased GHGs that, compared to the observed changes seen in Fig. 6, are too small and of the wrong sign.

Let us now assume that there is some non-longwave stratospheric heating, $Q_{s}$, due for example to the presence of ozone. If this is balanced by longwave cooling we have

$$
\frac{\partial I}{\partial z}=\rho c_{p} Q_{s}=Q
$$

where for convenience we define $Q \equiv \rho c_{p} Q_{s}$. Combining the two equations in (3.2) we obtain

$$
\frac{\partial^{2} I}{\partial \tau^{2}}=I-2 \frac{\partial B}{\partial \tau}
$$

Now, from (3.8) we have

$$
\frac{\partial I}{\partial \tau}=-\frac{H_{a}}{\tau} \frac{\partial I}{\partial z}=-\frac{H_{a}}{\tau} Q
$$

so that, differentiating once more and using (3.8) again,

$$
\frac{\partial^{2} I}{\partial \tau^{2}}=\frac{H_{a}}{\tau^{2}} Q+\frac{H_{a}^{2}}{\tau^{2}} \frac{\partial Q}{\partial z} .
$$

Similarly, using (3.8), the last term on the right-hand side of (3.12) may be written

$$
\frac{\partial B}{\partial \tau}=-\frac{H_{a}}{\tau} \frac{\partial B}{\partial z} .
$$

Using (3.14) and (3.15), equation (3.12) becomes

$$
\begin{gathered}
\frac{\partial B}{\partial z}=-\frac{\tau}{2 H_{a}} I+\frac{1}{2 \tau} Q+\frac{H_{a}}{2 \tau} \frac{\partial Q}{\partial z} . \\
\text { Prepared using qjrms4.cls }
\end{gathered}
$$


If $Q=0$ this equation reduces to (3.9). For simplicity assume the heating is deep and that the last term on the right-hand side is small. Suppose also that $Q>0$, in which case there is a balance between longwave cooling and diabatic heating. Evidently, a sufficiently strong diabatic heating, or a sufficiently small optical depth $\tau$, will cause the temperature in the stratosphere to increase with height, even if the heating itself has no vertical structure.

Now consider what happens when $\tau$ increases in the case in which the baseline stratospheric temperature is increasing with height. At a given height the second term on the right hand side becomes significantly smaller causing the increase in temperature with height to diminish, and this will outweigh any change in the first term when $\tau$ is, realistically, small. If the temperature of the lower stratosphere stays approximately the same (because the outgoing longwave radiation is constrained) then the the stratosphere will cool. By the same token, if there is diabatic cooling in the stratosphere then an increased concentration of greenhouse gases will lead to stratospheric heating. The changes are much larger than in the radiative equilibrium case because of the presence of the optical depth in the denominator in the $Q$ terms.

An additional effect is possible simply because of the increase in height of the tropopause. If $Q$ is positive everywhere, and if the tropopause increases in height but stays at nearly the same temperature, then from (3.16) the stratosphere will cool even if $Q$ and $\tau$ are unaltered in the stratosphere and $\partial B / \partial z$ is unaltered. The reason is simply that the lower boundary condition - namely the nearly-fixed value of $B$ at the tropopause - then occurs at a higher value of $z$, so that at a fixed height above the tropopause temperature falls. However, in reality this effect is small because there is little ozone heating in the lower stratosphere so that the lower stratosphere is almost isothermal. Thus, cooling in reality occurs mainly in the mid- and upper stratosphere because of a small increase in $\tau$ and a reduction of $\partial B / \partial z$. The two effects described above are illustrated in Fig. 11.

From a physical perspective, the vertical structure of the stratospheric temperature is governed by a balance between infrared cooling and shortwave heating, and if the optical depth increases then the effects of the heating diminish and the stratosphere cools. That is, because optical depth increases with greenhouse gases, longwave radiation is more efficient (i.e., the radiative time-scale shortens) and there doesn't need to be as much longwave cooling to balance the same prescribed shortwave heating, and so temperature falls. A relevant discussion is given by Ramaswamy et al. (2001), who note that when $\mathrm{CO}_{2}$ increases there is only a small increase in absorption in the stratosphere but a larger one in emission, leading to cooling. The above argument does not depend on the detailed distribution of the absorption bands of carbon dioxide or water vapour, although the fact that the $15-\mu \mathrm{m}$ band of $\mathrm{CO}_{2}$ is saturated over short distances so that most of the upwelling radiation in the stratosphere comes from the upper troposphere will certainly play a quantitative role. However, the effect does depend on the presence of a non-IR heating, such as the shortwave heating provided by ozone, and its amplitude depends on the smallness of the stratospheric optical depth. The argument also explains why the temperature increases (with height) in the stratosphere when $Q$ itself has no structure: since the radiative time scale increases upward in the stratosphere, temperature must increase in order that the longwave cooling can balance the same shortwave heating.

From a mathematical perspective, the changes in temperature of both troposphere and stratosphere with increased greenhouse gases arise because of the change in the mapping of $\tau$ to $z$ - for note that $\tau$ is an independent variable in (3.1) so that an increase in greenhouse gases does not affect the equation except through the boundary conditions which occur at a fixed $z$. (See Ingram (2010). A somewhat related argument is made by Singh and O'Gorman (2012) who interpret changes in the vertical structure with greenhouse gases in terms of a rescaling of the vertical coordinate.) At any given height an increase in greenhouse gases causes $\tau$ to increase, and at any given $\tau$ the height will increase. In the troposphere the temperature falls with height and if the temperature at a given $\tau$ is to stay about the same then the temperature must increase at a given $z$. The tropopause height must then increase as its temperature is approximately fixed by the OLR constraint. If the stratospheric basic state is such that the temperature increases with height then the situation is reversed and its temperature will fall.

\subsection{Tropopause increases and stratospheric cooling}

To provide a quantitative calculation that allows changes in both the tropospheric height and the stratospheric temperature requires a numerical calculation, and to do this we proceed as follows. Equations 3.1 are solved numerically with $\tau(z)$ specified and with a top boundary condition of $D=0$ and $U=O L R$, where $O L R$ is a constant. The boundary condition at the bottom is that $U=\sigma T_{s}^{4}$, but $T_{s}$ is initially unknown. We divide the atmosphere into two regions, a troposphere extending up to a height $H_{T}$ that has a specified 

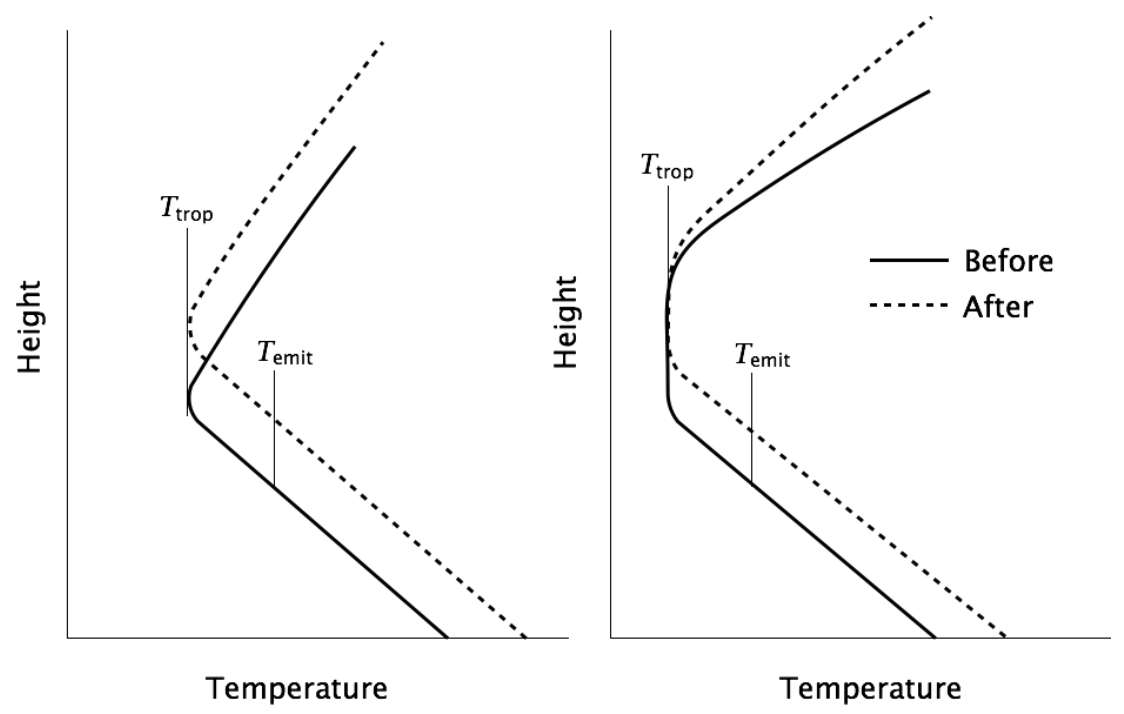

Figure 11. Schematic of change in temperature profiles and tropopause height and before and after global warming. The tropopause temperature is constrained to be nearly constant so it must increase in height. If the temperature increases with height everywhere above the tropopause then stratospheric temperature will fall with warming, even if the stratospheric lapse rate is unaltered, as in the left panel. More realistically, as in the right panel, the lower stratosphere is more nearly isothermal and the upper stratospheric cools because its lapse rate changes.

stratification, $\Gamma$, and a stratosphere in which the radiative forcing is specified and satisfies $\partial I / \partial z=Q$ with a specified $Q(z)$ and with a boundary condition of with $U=S_{0}$ and $D=0$ at the top. Within the stratosphere the specification of $Q$ determines $U-D$ and we numerically integrate (3.2b) to obtain $U+D$, and thence obtain the temperature from (3.2a). Within the troposphere the temperature is specified via the lapse rate, and the upward and downward irradiances are then calculated using (3.1). For an arbitrary choice of tropospheric height this procedure does not produce a self-consistent solution because the upward irradiance at the surface, $U_{s}$ will not equal $\sigma T_{s}^{4}$. Alternatively, were we to specify a boundary condition of $U_{s}=\sigma T_{s}^{4}$, we would find that the outgoing longwave radiation was not equal to the net incoming solar radiation. Either way, the tropospheric height may be thought of a being determined by the requirement that column as a whole is in radiative balance, and the tropopause height is adjusted and the calculation iterated until a proper balance is achieved.

The results of such a calculation are shown in Fig. 12. We show three pairs of calculation - a pair with shortwave heating in the mid- and upper stratosphere, a pair with cooling in the mid- and upper stratosphere, and a pair with no stratospheric heating (and so in longwave radiative equilibrium). In each case we show the temperature profile in a control simulation (with $\tau_{0}=4 \times 2 / 3$ ) and a case in which the optical depth is increased by $50 \%$ (which is a large increase, to show the effect) with the temperature differences in the three cases shown in Fig. 13. In each case the tropopause height increases by about the same amount, but only in the case with a stratospheric heating does the stratosphere cool. The lower stratosphere, which in all cases has no shortwave heating or cooling, remains almost isothermal and its temperature hardly changes.

\section{Changes to the Midlatitude Circulation}

We now consider the possible shift in latitude of the midlatitude circulation, an in particular of the surface westerlies, in a warmer climate. A poleward shift of the storm track was noted by Hall et al. (1994) in simulations with doubled carbon dioxide, by Yin (2005) in a number of integrations of future climates in the CMIP3 archive, and recently Barnes and Polvani (2013) noted a poleward shift of the midlatitude jets in some of the CMIP5 integrations. In general consistency with these simulations a number of authors have documented poleward trends in the observed or reanalysed position of the midlatitude jets, storminess, and/or the relevant annular mode over the past few decades (Thompson and Solomon 2002; Archer and Caldeira 2008; Chen and Held 2007; Solman and Orlanski 2014; Bender et al. 2011). However, some equatorward shifts have also been seen in simulations of future climates using models that have a welldeveloped stratosphere Scaife et al. (2012); Karpechko and Manzini (2012).

\subsection{Model results}

Figure 14 shows the mean zonal winds at year 1 and year 70 , and their difference (actually obtained by 

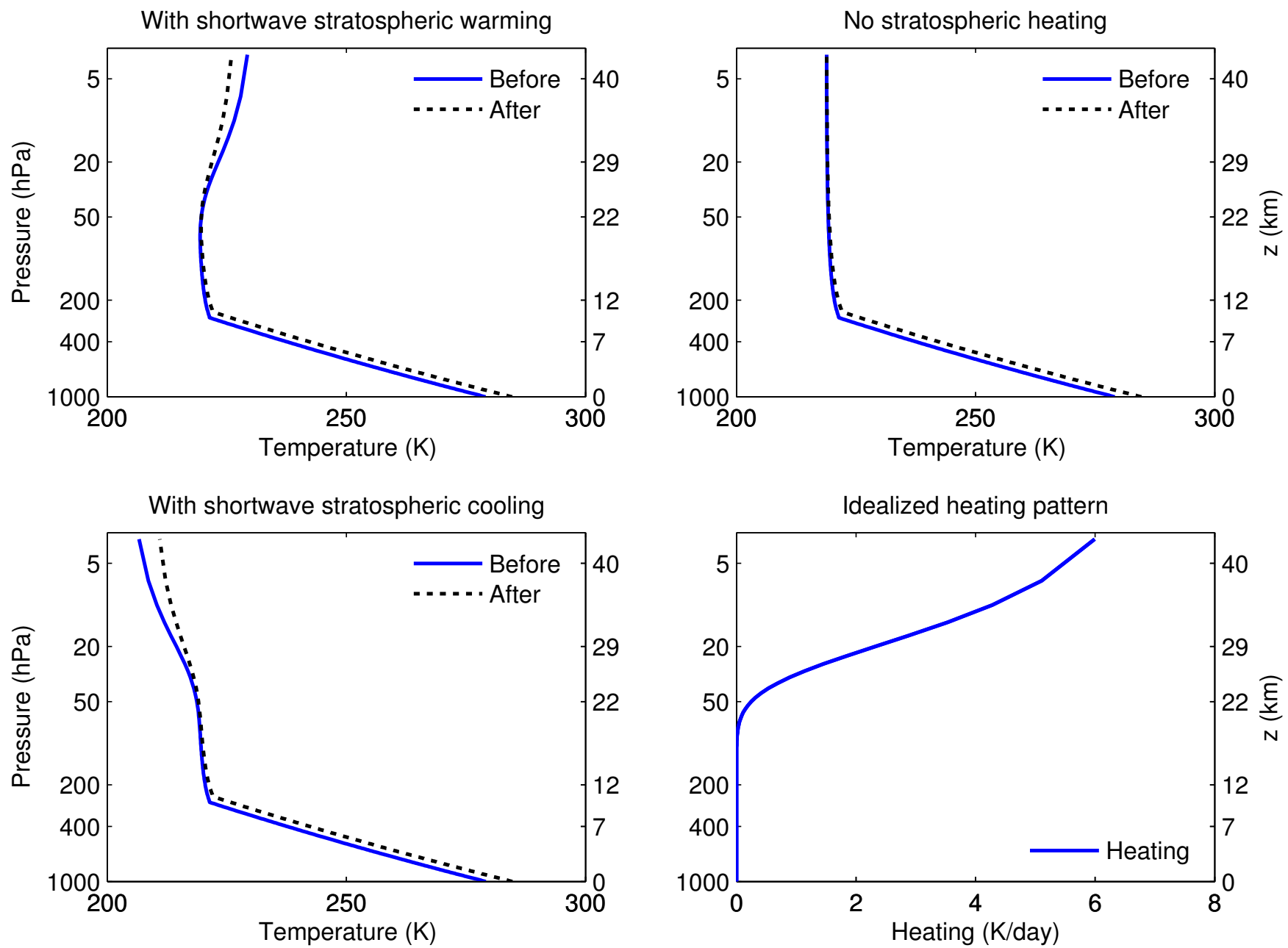

Figure 12. Temperature changes in a radiative-convective model obtained by increasing the optical depth of the atmosphere, $\tau_{0}$. The blue lines are the control temperature profiles and the dashed black lines are the temperature profiles after a small increase in $\tau_{0}$. The three cases have, as labelled, non-IR stratospheric heating (e.g., shortwave heating such as ozone, with the heating illustrated in the lower right panel), no stratospheric heating, or non-IR (shortwave) stratospheric cooling. In all cases there is an increase in the height of the tropopause, but in only one case (the top left) is there stratospheric cooling, as is observed.

from a least-squares fit to the trend from year 1 to year 70) for the models in the CMIP5 $1 \%$ ensemble. There are small but consistent shifts in the latitude of the maximum surface westerlies, as seen in Fig. 15. In these plots the westerlies were taken from the linear fit to $\bar{u}_{s}$ at each latitude evaluated at year 1 and year 70 , and the latitude of the maximum was found from a quadratic fit of the data about one point either side of the maximum, and the fit was evaluated where its analytic derivative was zero. Except in the Northern Hemisphere summer in the 1\% ensemble there is a polewards shift of the surface westerlies in both hemispheres of about $1^{\circ}$ for a over the 70 year period. There is a correlation, but only a weak one, between the shift in the Southern Hemisphere and that in the Northern Hemisphere. Also, the shift itself is no larger than the intermodel variability of the shift, as can be seen by inspection of Fig. 15 and Fig. 16.

The shift in latitude is weakly correlated with the latitude of westerlies themselves, as seen in Fig. 17. That is to say, models with jets that in today's climate are more equatorward tend to shift them a little further polewards under global warming, but the correlation is rather weak, and is in fact even weaker in the RCP8.5 integrations (not shown). A good correlation between the climatological jet latitude and its shift, in austral summer, was found by Kidston and Gerber (2010), and it may be that a more detailed examination of seasonal effects in individual models is needed to fully understand the results.

Finally, there is also only a very weak correlation between the shift and the TCR (i.e., the globally averaged surface temperature increase from year 


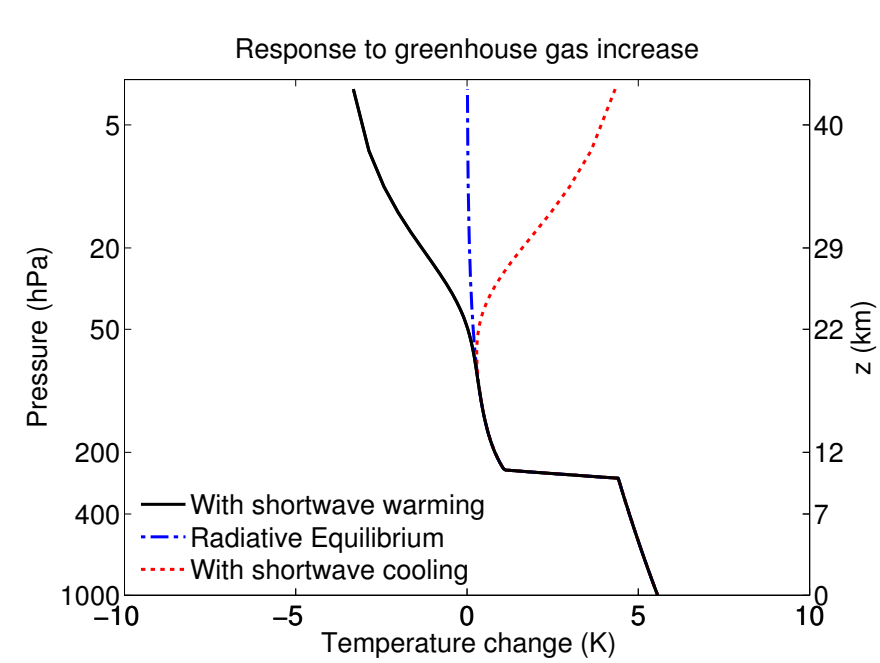

Figure 13. The actual temperature increase in the three cases illustrated in Fig. 12.

1 to year 70) across models (Fig. 18). Grise and Polvani (2014) did find a somewhat larger correlation between climate sensitivity and jet shifts in the $4 \times \mathrm{CO}_{2}$ ensemble in the Southern Hemisphere, but only during DJF and MAM.

The strength of the surface westerlies also show some interesting trends. In boreal summer (JJA) the surface winds in the Northern Hemisphere exhibit a near-universal weakening across models whereas in the Southern Hemisphere in the austral summer (DJF) the winds show a near universal strengthening. In the respective winters the Southern Hemisphere winds again show a consistent strengthening, whereas in the Northern Hemisphere there is no consistent response across models. These marked differences in hemispheres may correspond to differences in the changes in baroclinicity in the Northern and Southern Hemispheres - low level polar amplification and a reduction in low-level baroclinicity is a Northern Hemisphere phenomenon and this may account for a weakening of the surface winds. In the Southern Hemisphere the low-level baroclinicity barely changes over 70 years whereas the mid- and upper level baroclinicity increases, and more so than in the Northern Hemisphere. However, the seasonality of the response is not obvious and further investigation of all this is left for future work.

\subsection{Some theoretical expectations}

The shifts and the changes in strength of the midlatitude circulation are still not well understood, and we will discuss a few candidate mechanisms without going into any detail on any of them. (We will see that that the physical arguments for Hadley Cell expansion are also not particularly compelling because (a)

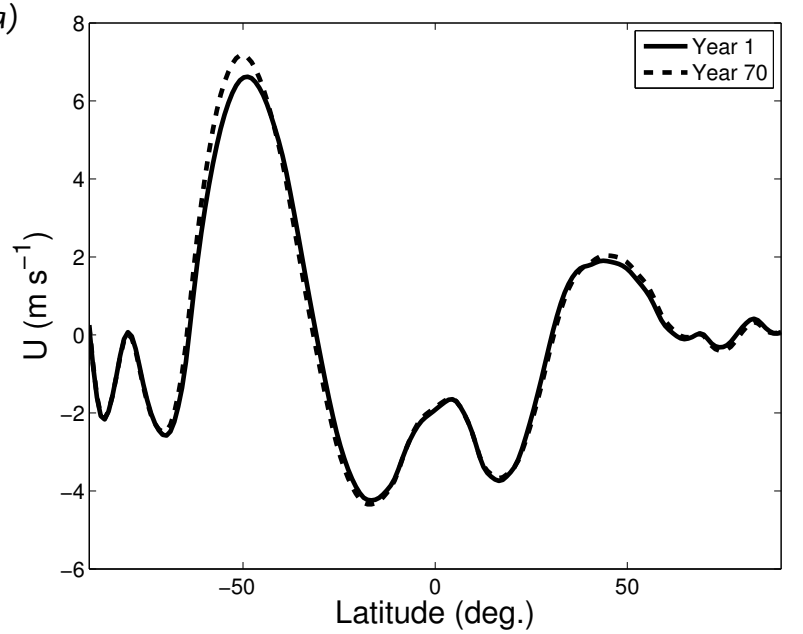

(b)

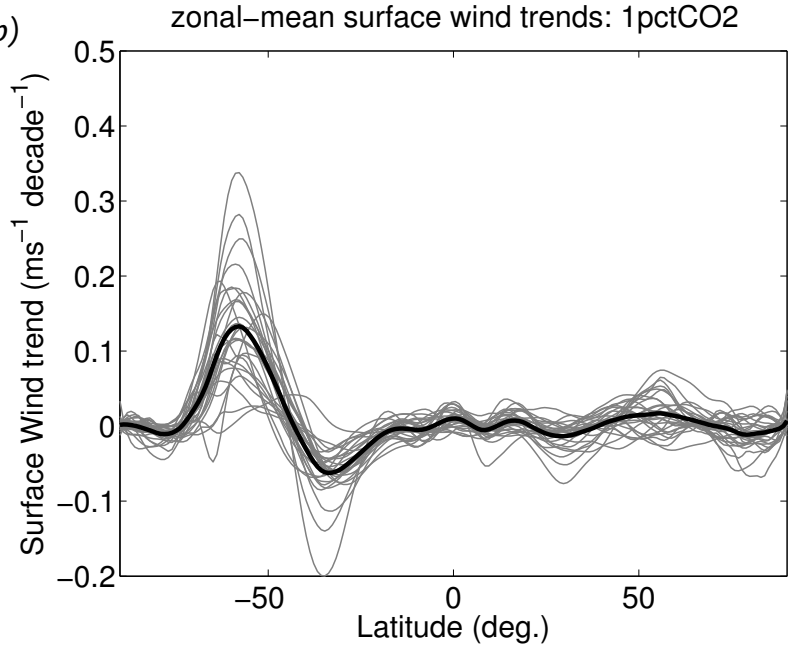

Figure 14. (a) The ensemble-mean zonal-mean near-surface zonal-wind speed $\left(\bar{u}_{s}\right)$ at year 1 (black) and year 70 (dashed) in the $1 \%$ integrations, calculated using the average trend (see text). (b) The thick black line is the difference between the two lines in (a), and the lighter lines are the corresponding differences for individual models.

they mostly rely on dry angular momentum conserving flow and/or overly idealized models of baroclinic instability, although the arguments themselves are reasonably straightforward and could be expected to hold in an appropriately designed model.) A starting point for the discussion is the change in the overall baroclinic structure of the atmosphere: from Fig. 6 we see that the upper tropospheric and lower stratospheric meridional temperature gradient is expected to increase whereas the near surface temperature gradient, at least in the Northern Hemisphere, is expected to decrease. The increase in the upper tropospheric meridional temperature gradient stems from robust thermodynamic effects (the change in moist adiabatic lapse rate with temperature) and any feedbacks in the dynamics seem unlikely to abate that significantly. The reduction in 

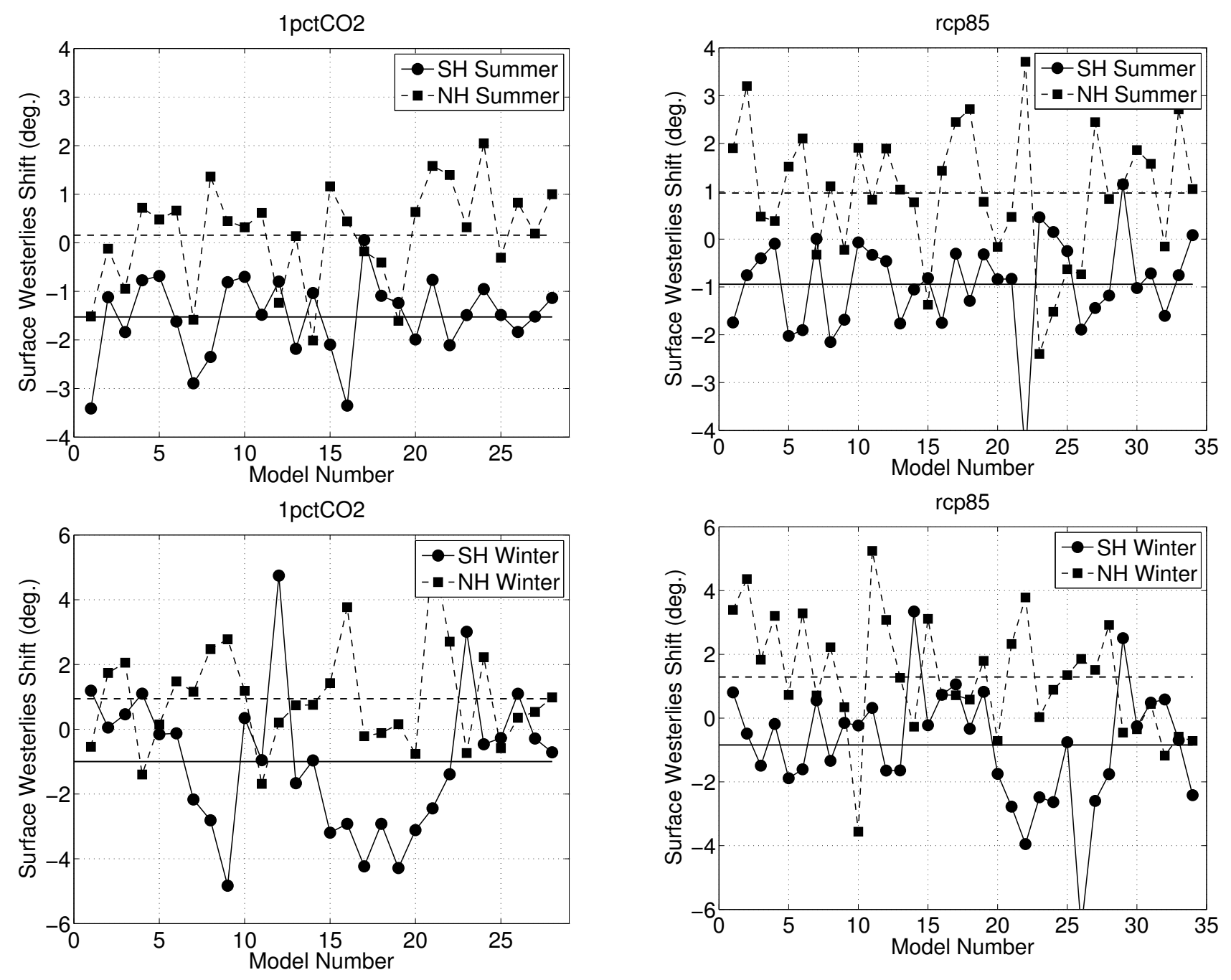

Figure 15. The change in the latitude of the maximum surface westerlies from year 1 to year 70, for models in the 1\% integrations, for the two hemispheres and their respective summer and winter seasons, as labelled. Dashed lines are Northern Hemisphere, solid lines Southern Hemisphere, and the horizontal lines are the ensemble means.

the low-level baroclinicity due to polar amplification depends on somewhat more subtle feedbacks, and does not occur in the Southern Hemisphere at least on decade-century timescales, but does occur across a broad spectrum of models and in that sense is robust.

Such a change in the thermal structure will almost certainly alter such baroclinic instability properties of the system, although if the basic state is sufficiently baroclinically unstable so that the resulting eddies are deep then one would expect it to be the vertically integrated meridional gradient of temperature that is important rather that its detailed vertical structure, and this seems consistent with the results of Pavan (1995). The situation is a little less clear in practice. In an idealized model, but in a realistic parameter range, Lunkeit et al. (1998) found that the eddy

Figure 16. Same as Fig. 15 but for RCP8.5 integrations.

activity was more sensitive to lower- than to upperlevel changes in baroclinicity. On the other hand, using the GFDL CM2.1 model (a comprehensive climate model) $\mathrm{Wu}$ et al. (2011) found that eddies were more influenced by baroclinicity in the upper troposphere than the lower. Thus, it is by no means self-evident just how such changes will affect the location of baroclinic instability without doing a detailed calculation, especially given that changes in static stability also affect the instability.

Nevertheless, there is some consistency the results of some comprehensive and idealized models (Wu et al. (2011) and Butler et al. (2010) respectively) that suggests a straightforward hypothesis. Warming in the tropical troposphere will tend to produce a slight poleward shift of the meridional temperature gradient which, in conjunction with a slight increase in the static stability of the subtropics, will tend to push the region of baroclinicity polewards, with the position of the storm track moving concomitantly. (Lu et al. 2010 
(a)

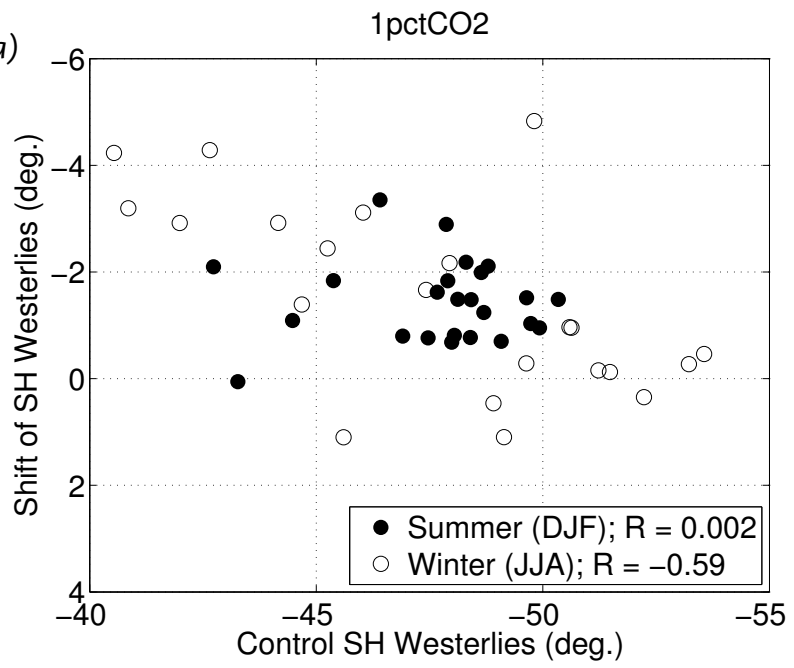

(b)

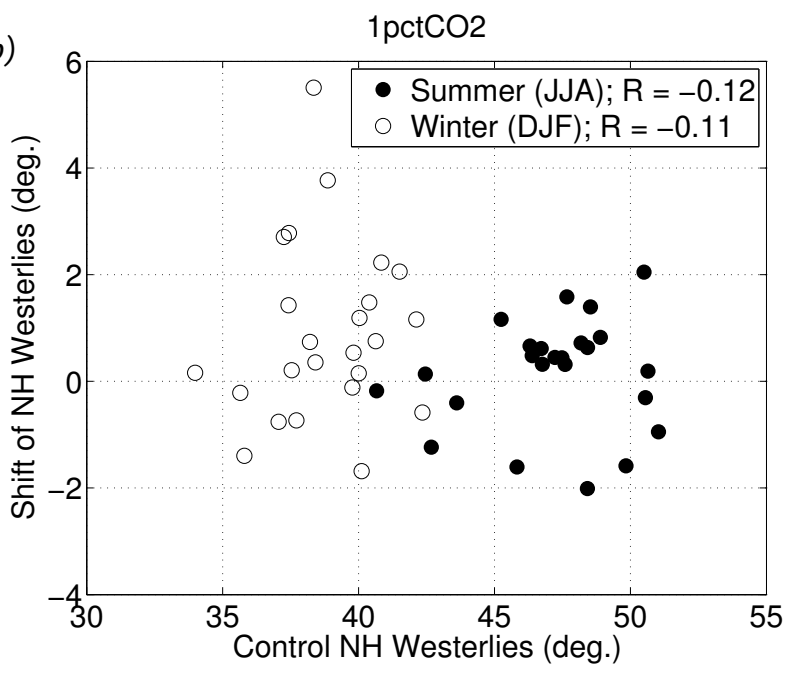

Figure 17. (a) Scatter plot for the Southern Hemisphere of the latitude of the surface westerlies in the control runs, versus the shift in the future, for the $1 \%$ integrations. (b) Same as (a) but for Northern Hemisphere. Polewards is to the right and top in both plots.

argue that the position of the eddy-driven westerlies is dominated by the eddy heat flux component of the EP flux, which is likely to be closely associated with the baroclinicity.) Indeed Butler et al. (2010) found, using an idealized dry model, that warming in the tropical troposphere pushed the extra-tropical stormtrack polewards. Complicating the issue is the fact that low level polar amplification may tend to push the baroclinicity and the storm tracks equatorward (Butler et al. 2010), but this is a predominantly Northern Hemisphere effect and figures 15 and 16 suggest that the effect may be small. In any case it is hard to come up with an a priori estimate in changes in baroclinicity without doing a detailed calculation that may have much uncertainty, and changes in the jet position in the CMIP5 models do tend to be small and the model scatter is large (figures 15 and 16). Still, and with due
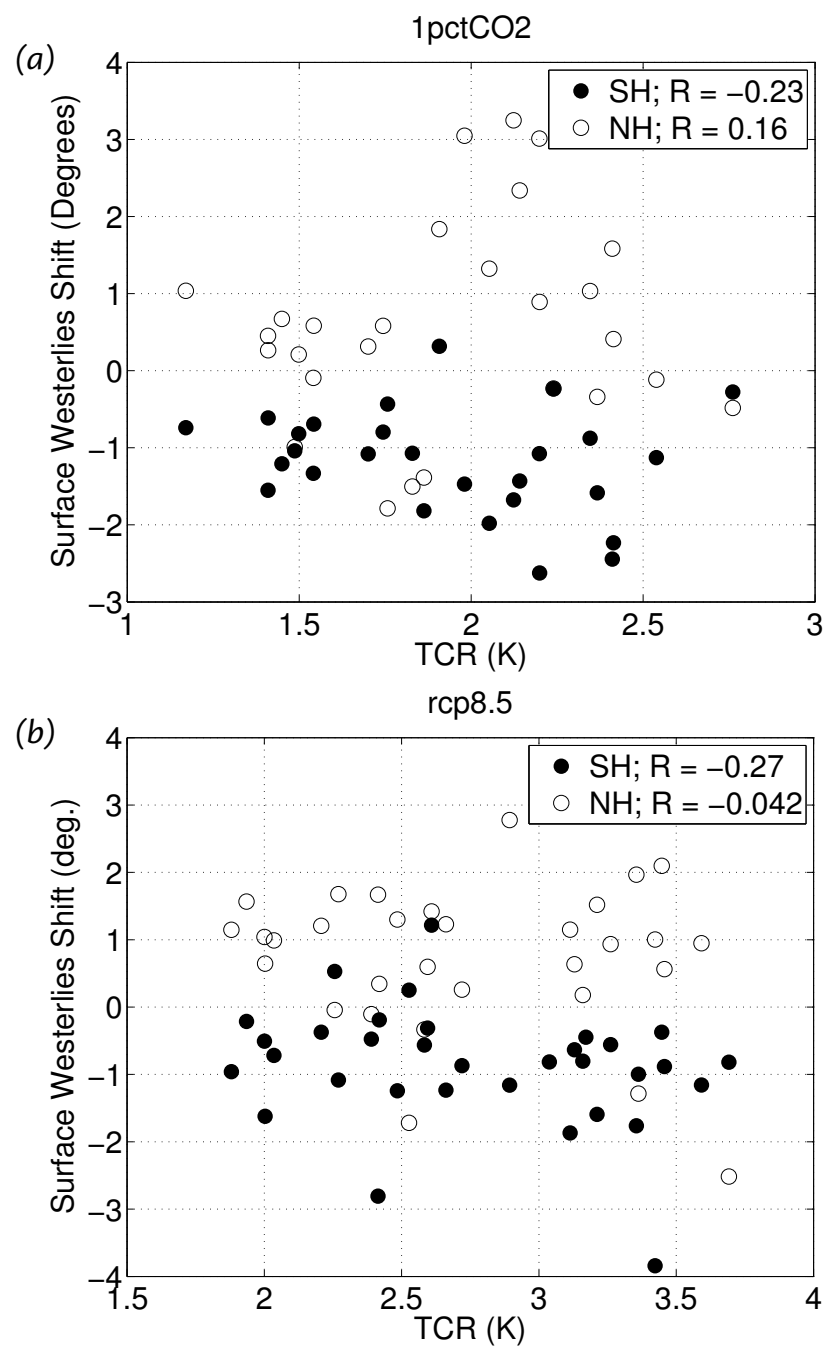

Figure 18. Scatter plot of TCR against annual average $\mathrm{SH}$ and $\mathrm{NH}$ westerly shift (black and grey respectively) for the $1 \%$ integrations (a) and RCP8.5 (b).

attention to caveats and uncertainties, one might say that changes in large-scale thermal structure of the troposphere leading to a poleward shift in baroclinic growth rates leading to a poleward shift in eddy fluxes and surface winds is a straightforward and potentially reproducible causal sequence that constitutes a simple and reasonably robust explanation for the trends in the mid-latitude.

The above mechanism is far from being so compelling as to be definitive, as also noted in the review by Schneider et al. (2010), and other plausible arguments may be made. Thus, Chen and Held (2007) and Chen et al. (2008) argue that, as a consequence of global warming, the phase speed of the midlatitude eddies increases. This leads to a shift in their critical latitude and, they argue, to a poleward shift of the eddy momentum fluxes and thence of the surface westerlies. A related argument has recently been proposed by 

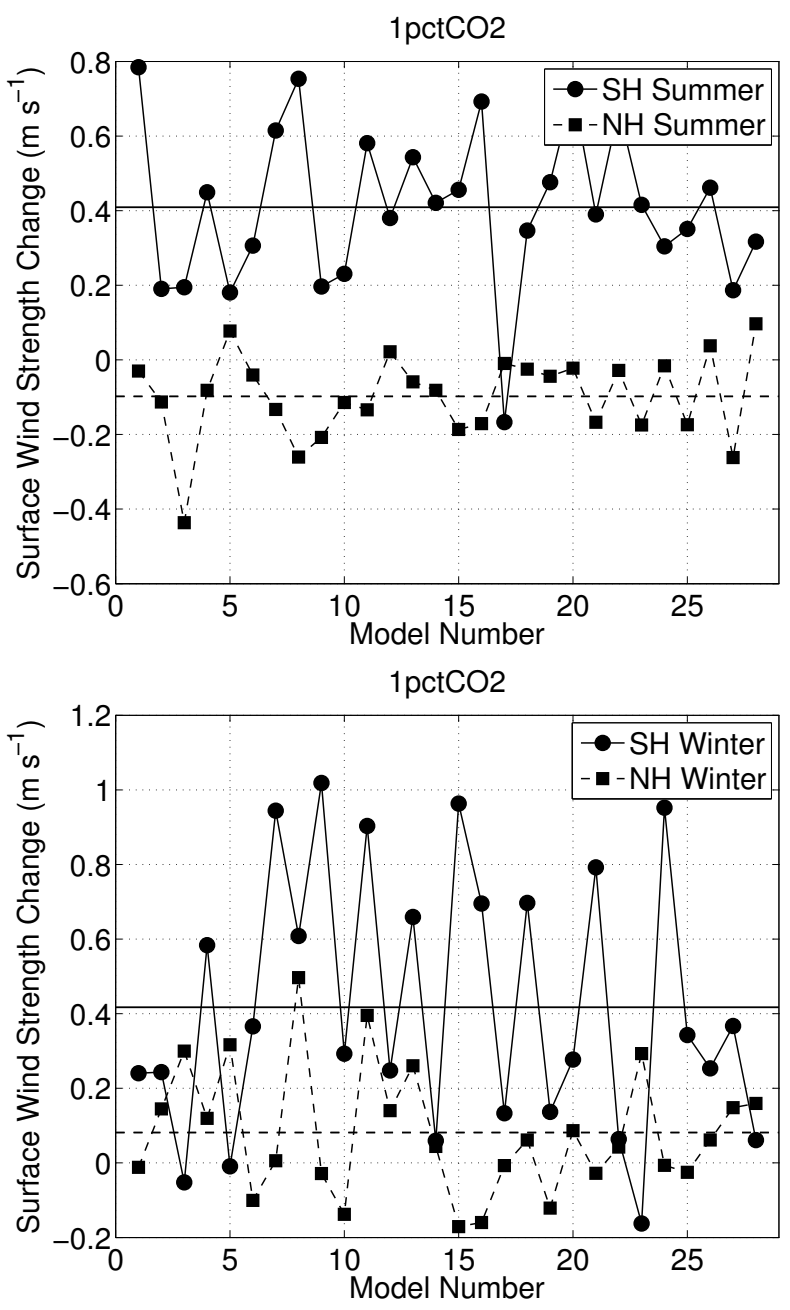

Figure 19. Change in strength of the surface westerly winds for models in the $1 \%$ ensemble over the 70 year period for summer and winter, and for Northern Hemisphere (dashed lines) and Southern Hemisphere (solid lines), as labelled. Horizontal lines are the ensemble means

Lorenz (2014); he proposed that a poleward shifted jet is maintained via a selective reflecting on the poleward flank of jet. For a given wavenumber, low phase speed waves are reflected but high phase speed waves are absorbed at a critical level. When the zonalmean zonal wind increases on the poleward flank of the jet, a wider range of poleward propagating waves are reflected instead of absorbed, and this leads to an more equatorward propagating waves, and so more poleward momentum flux, across the jet. A general prediction of this mechanism is that any forcing that causes the westerlies to get stronger also shifts the jet polewards, as in (Kidston and Vallis 2012). This mechanism is neither supported nor eliminated by the CMIP5 results we have presented. In nearly all cases the increase in strength of the westerlies is significantly larger in the Southern Hemisphere than in the Northern Hemisphere, and in the Northern Hemisphere summer the jets weaken (Fig. 19). However, there is a poleward jet shift in both hemispheres and seasons, albeit a little larger in the Southern Hemisphere, especially in summer (figures 15 and 16). However, the differences between Northern and Southern Hemispheres make this comparison suspect, and our comparisons only show surface winds. The above mechanism also has similarities with the work Kidston et al. (2011) who suggested that an increase in the eddy length scale leads to a change in zonal phase speed which in turn shifts the poleward flank of eddy dissipation region polewards of the eddy generation region, allowing the jet to move poleward. Lorenz and DeWeaver (2007), building in part on work of Williams (2006), show that an increase in tropopause height can lead to a shift of the westerlies and, since we have demonstrated that an increase in tropopause height is an almost inevitable consequence of warming, the mechanism is also plausible. However, the increase in tropopause height appears to be a more robust result than the poleward trending of the westerlies, implying that the tropopause height is not the sole influencing factor.

Regarding the stratospheric influence, a strengthening of the Brewer-Dobson circulation with global warming (as is commonly predicted by climate models: Butchart and Coauthors 2006; Oman et al. 2009; Shepherd and McLandress 2011) could lead to a weakening of the polar vortex (as too would a recovery of the ozone in the Southern Hemisphere). This could lead to an equatorward trend of the midlatitude jet (Polvani and Kushner 2002; Polvani et al. 2011), and may be a cause of the seemingly anomalous results of Scaife et al. (2012), obtained with models with better stratospheric resolution. Scaife et al ascribe the equatorward shift to an initial equatorward shift in the stratospheric jet arising from increased wave activity convergence there, producing a dipole in the winds near the troposphere. Easterly anomalies at high latitudes and westerly anomaly at low latitudes change the upper tropospheric baroclinicity and the latitude of the tropospheric storm track moves south as a consequence. How robust this mechanism is in other models remains to be seen. Finally, on a very different tack, Allen et al. (2012) show that increases in black carbon aerosols and tropospheric ozone can affect the thermal structure of the troposphere sufficiently to cause a poleward shift of the jet and, concomitantly, a tropical expansion. We also note that there are some biases in jet latitude in CMIP5 jet latitudes associated with shortwave cloud forcing (Ceppi et al. 2012), so it seems plausible for changes in cloud or aerosol radiative forcing to change the position of the jet. 
Evidently, and given all these various arguments concerning changes in jet strength and latitude, whether a single mechanism is the dominant one and what that mechanism is, or whether some combination applies, remains to be determined.

\section{The Hadley Cell}

We now turn our attention to the Hadley Cell and its possible changes in extent and strength as the climate warms.

\subsection{Latitudinal structure}

Various studies (e.g., $\mathrm{Hu}$ and Fu 2007; Seidel and Randel 2007, and others as reviewed by Seidel et al. 2008) have found that the Hadley Cell has, in fact, expanded to a greater or lessor extent over the past few decades - indeed from tropopause observations Seidel and Randel (2007) suggest that the tropical belt may have widened by as much as $5^{\circ}-8^{\circ}$ from 1979-2005! A note of caution to such large estimates was injected by Birner (2010), who noted that trend estimates for the width of the tropical belt are not all consistent with each other; nevertheless, that there is a slight widening trend of the Hadley Cell has become widely accepted. Various models, both idealized and comprehensive, have also simulated a widening trend, if not always as noticeable as that suggested by some of the observations (Frierson et al. 2007; Lu et al. 2008; Tandon et al. 2013). For example, Frierson et al found an increase in Hadley Cell width of about 0.25 degrees per $1 \mathrm{~K}$ temperature increase, similar to that found in some of the CMIP3 integrations by Lu et al. (2007).

\section{Model results}

Comprehensive models undergoing global warming in the CMIP5 do show a small but noticeable expansion in the latitudinal extent of the Hadley Cell, as illustrated in Fig. 20 and Fig. 21. We used two distinct criteria to evaluate the width of the Hadley Cell, one based on overturning streamfunction and the other on zonal surface wind. We also evaluated two measures of overturning circulation: one is to simply state that the Hadley Cell terminates where the value of the Eulerian overturning circulation at $500 \mathrm{hPa}$ goes to zero, and the second measure is the evaluate the latitude at which the value of the overturning circulation drops to $10 \%$ of its maximum value at $500 \mathrm{hPa}$ (similar to that of Kang and Lu 2012; Kang et al. 2013). Of these two measures, we judged the second method to give slightly fewer artifactual results and present only those results. We still had to eliminate results for which the Hadley Cell was very poorly defined, in particular results in which the overturning streamfunction passed through zero at more than one latitude, a not uncommon circumstance in the summer cell. Our second criterion is to evaluate the latitude where the zonally averaged zonal wind passes through zero. This is not a universal measure (it would not work well in a climate with no baroclinic activity) but it is a useful and easily evaluated criterion for climates similar to that of today. We performed the analysis for all seasons and annular mean and found a distinct expansion of the Hadley Cell using both criteria (Fig. 20), mainly but not solely confined to the winter - we found distinct but smaller summer expansion in the Southern Hemisphere using the surface wind criterion, and the expansion projects onto the annual mean (Fig. 21). Using the Community Atmosphere Model Kang et al. (2013) found a widening of the Hadley Cell in both hemispheres but only in the winter season, using the streamfunction criterion. The two criteria (surface wind and streamfunction) correlate well with each other $(R \approx 0.9)$ for each season except for Northern Hemisphere summer, where the correlation drop to about 0.3. This is perhaps not surprising because the overturning streamfunction is particularly poor in Northern Hemisphere summer when the Hadley Cell is very weak.

Although the similarity in the results using two different methods does suggest some robustness, the ensemble mean change of the winter Hadley Cell width over the 70 year period is in fact barely larger than inter-model standard deviation of the trend, dependent on scenario and the measure by which the Hadley Cell extent is measured. There is also very little correlation across models between the shifts in the two hemispheres. In the $1 \%$ ensemble the winter expansion is about $0.8^{\circ}$ whereas in summer it is about half that, over a period in which the average temperature rises by just under $2 \mathrm{~K}$. However, the scatter, especially in summer, is large and too much weight should not be ascribed to the precise number. In summer the Hadley Cell is weak and can be poorly defined. Thus, for example, in one model the summer Hadley Cell expansion using the streamfunction metric is calculated to be $5^{\circ}$, which skews the average, but in that model the summer cell is barely discernible. For the RCP ensemble the annual-average expansion is about $0.5^{\circ}$ and $0.8^{\circ}$ in the Northern and Southern Hemispheres respectively over a period in which temperature rises on average by about $2.5 \mathrm{~K}$. We may summarize these results by saying that there is a discernible expansion of the Hadley Cell of less than $0.5^{\circ}$ latitude per degree Kelvin of warming, with a larger or at least more discernible expansion in winter and a fair amount of inter-model scatter. 

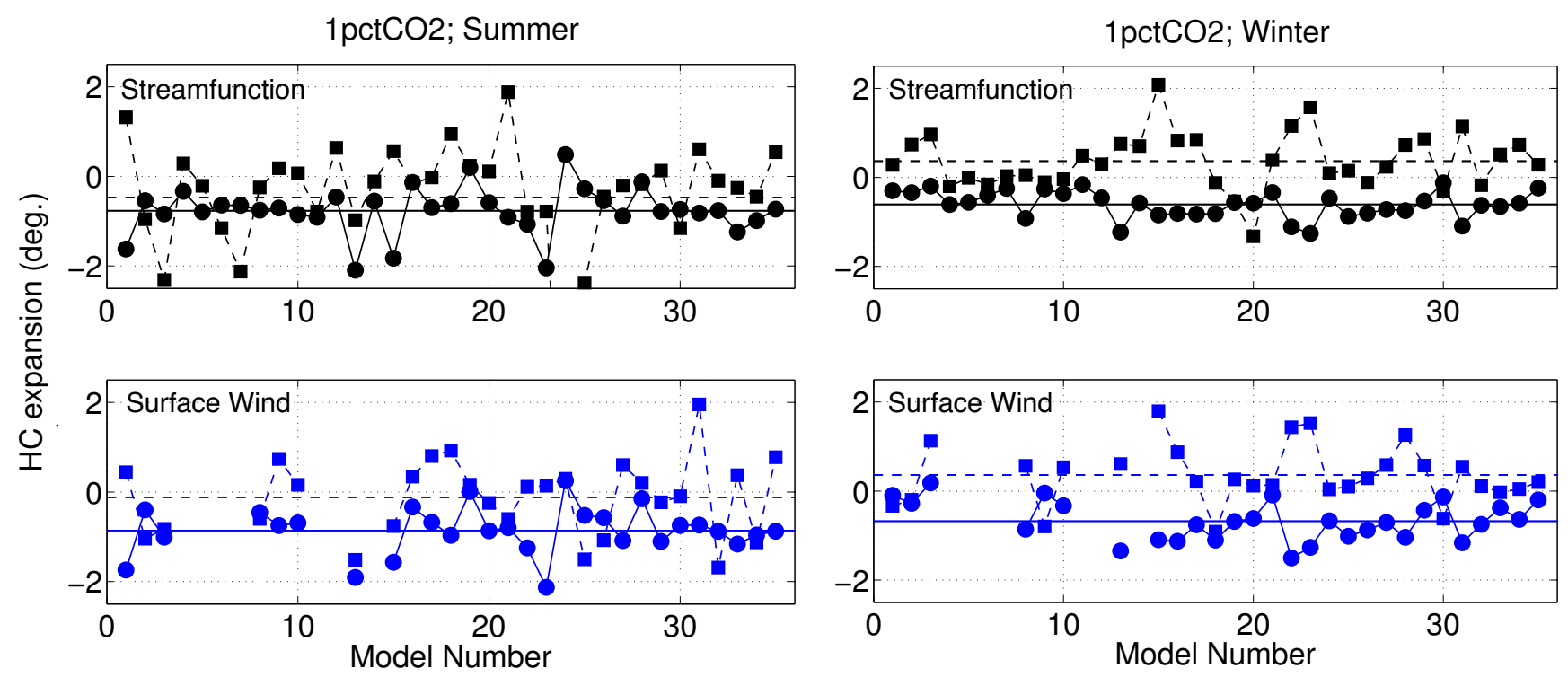

Figure 20. Change in the latitude of the edge of the Hadley cell for models in the $1 \%$ scenario over a 70 year period (and so over a $\mathrm{CO}_{2}$ doubling). The left panels shows summer and the right panels show winter. Dashed lines with squares are Northern Hemisphere and solid lines with circles are Southern Hemisphere, computed with an overturning streamfunction criterion and a surface wind criterion, as labelled, and the horizontal lines are the ensemble means for the given season and hemisphere. The model numbers refer to the same models across panels.

The Hadley Cell expansion is not especially well correlated with the TCR, as seen in Fig. 21, which shows a scatter plot of the Hadley Cell expansion in each hemisphere against the 'TCR' for the RCP8.5 scenario. (By TCR for the RCP8.5 simulations we mean the globally averaged surface temperature increase from year 1 to year 70.) A similar result (i.e., little correlation between dynamical sensitivity and thermal sensitivity) is obtained when the results are divided into seasons as well as when using the 1\% ensemble, although there is small positive correlation in Northern Hemisphere winter (not shown). This is not equivalent to saying that for any given model the Hadley Cell expansion will not increase with the global temperature increase, and indeed the expansion in the RCP8.5 ensemble is a little larger than in the $1 \%$ ensemble. However, the result does suggest that that the relationship between the TCR and Hadley Cell expansion is not the same for all models. This result stands in some contrast to that of Grise and Polvani (2014) who found that the expansion of the Hadley Cell was fairly well correlated with climate sensitivity in the Southern Hemisphere in all seasons in the CMIP5 abrupt $4 \times \mathrm{CO}_{2}$ integrations, although given the delicacy in the computation of the expansion of the Hadley Cell - note the detailed differences in the results of the two criteria used in Fig. 20 - perhaps too much weight should not be ascribed to that. Furthermore, Grise and Polvani consider the

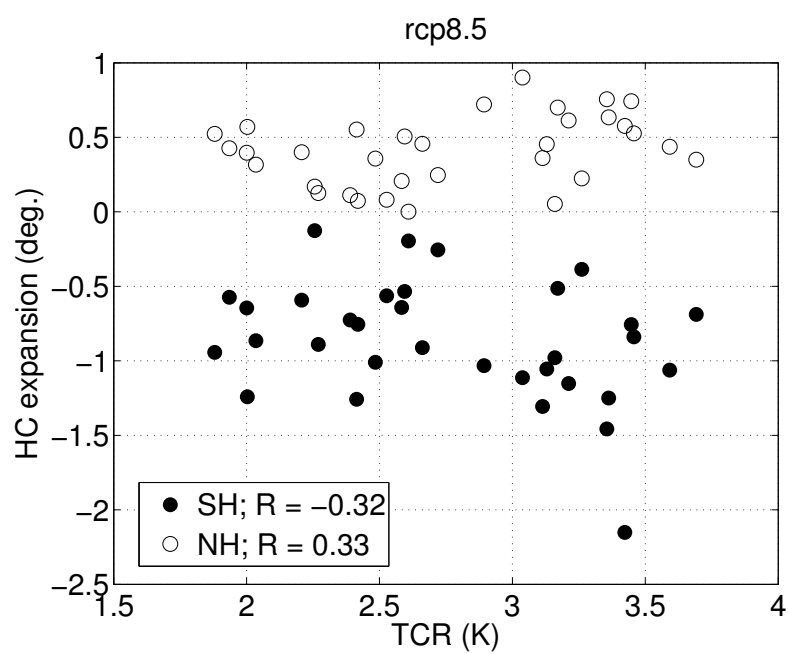

Figure 21. Scatter plot of Hadley Cell expansion and TCR for the Northern Hemisphere (open circles) and Southern Hemisphere (black dots) for the RCP8.5 ensemble for annual mean conditions, with the Hadley Cell extent determined using surface winds. Similar results (i.e. a low correlation) are found on a seasonal basis and for the $1 \%$ ensemble.

equilibrium climate sensitivity whereas we consider the transient.

We do find some correlation, across models, between the expansion of the Hadley Cell and the shift of the mid-latitude westerlies, with a notably higher correlation when using the surface wind criterion (Fig. 22 and Fig. 23). Using the surface wind criterion, in the Southern Hemisphere there is a strong positive 
(a)

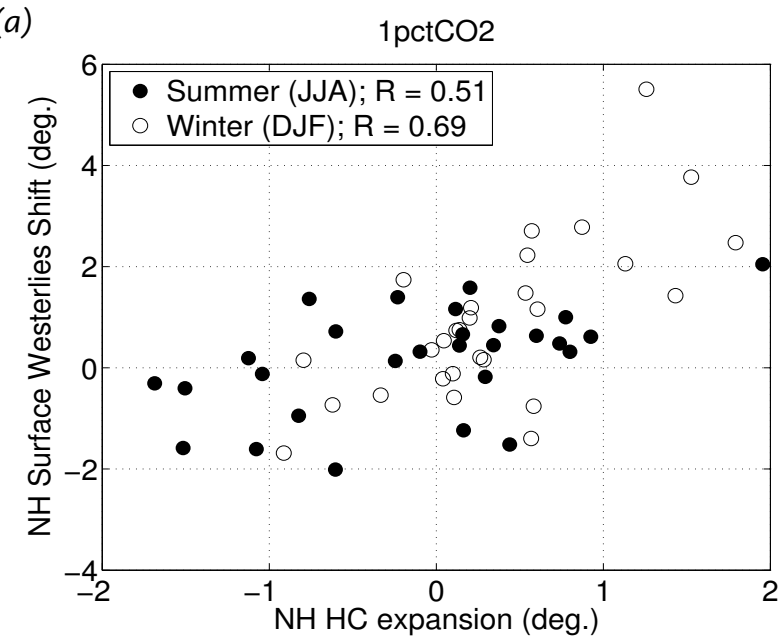

(b)

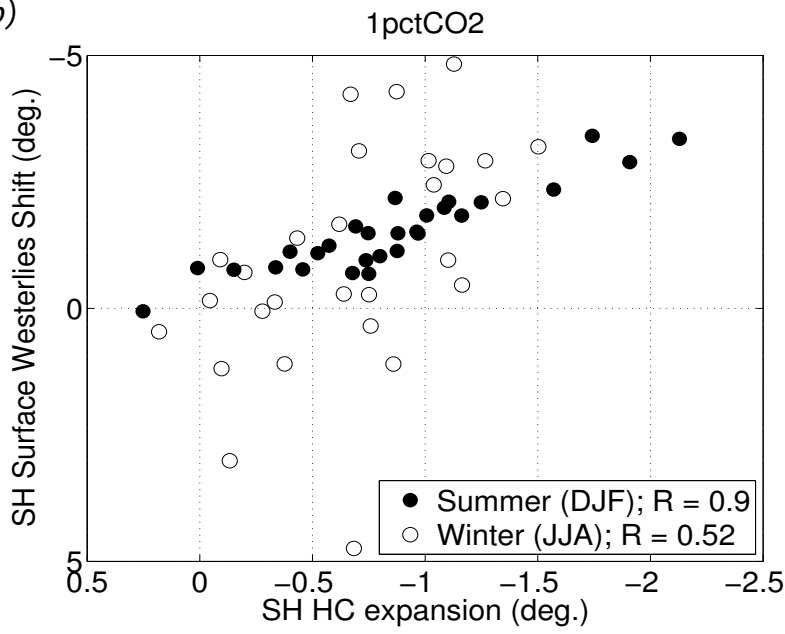

Figure 22. Scatter plot of the HC expansion vs shift of the westerlies for (a) the Northern Hemisphere, and (b) the Southern Hemisphere. A zero-crossing of the surface zonal winds is used as a measure of the extent of the Hadley Cell.

correlation $(R=0.9)$ between the expansion of the Hadley Cell and the shift of the surface westerlies in austral summer, with a smaller correlation $(R=$ $0.52)$ in austral winter. In the Northern Hemisphere there is a positive correlation in both winter $(R=$ $0.69)$ and summer $(R=0.51)$, but the latter reduces almost to zero using the using the streamfunction criterion. (The Notthern Hemisphere summer Hadley Cell can be poorly defined and its extent is subject to error when calculated using a streamfunction.) Positive correlations between Hadley Cell expansion and midlatitude shifts were previously found by $\mathrm{Lu}$ et al. (2008) in CMIP3 in the summer seasons, and by Kang and Polvani (2011) in austral summer on interannual timescales.

\subsection{Theoretical interpretation}

If the circulation were zonally symmetric then we might expect that the outgoing branch of the Hadley (a)

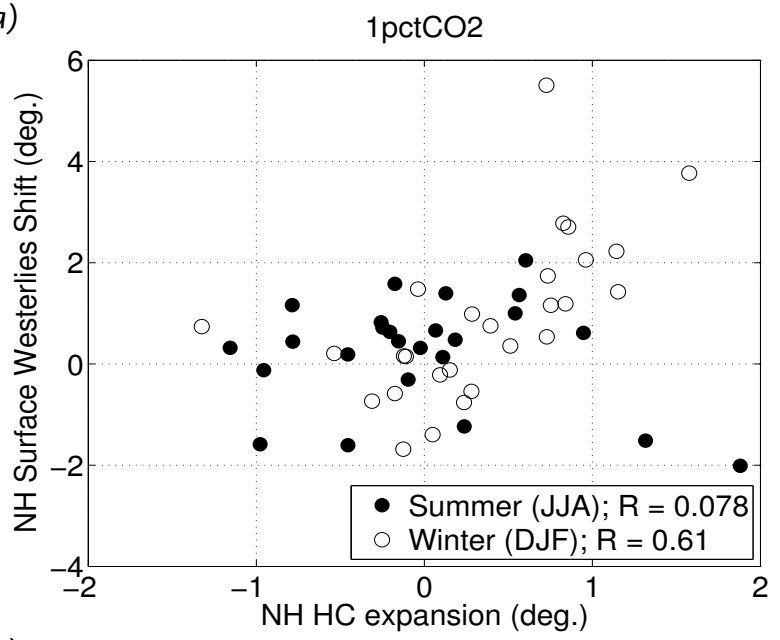

(b)

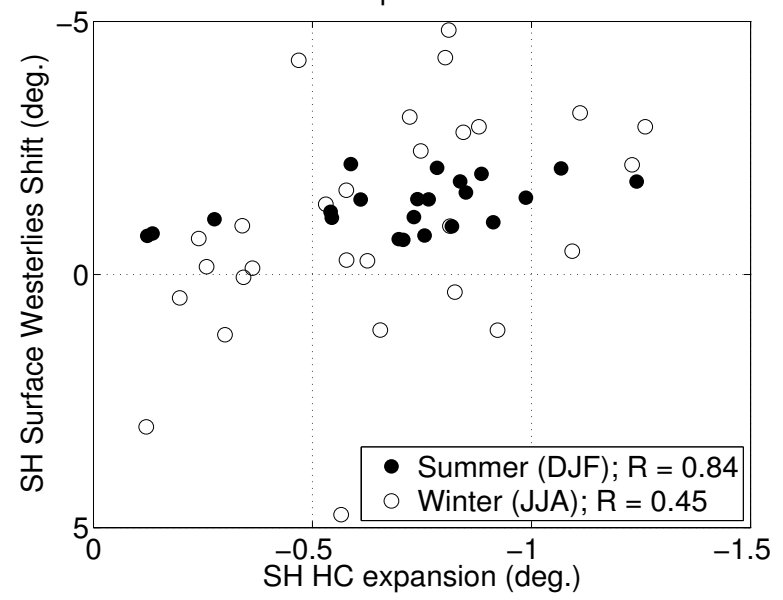

Figure 23. Scatter plot of the HC expansion vs shift of the westerlies for models in the $1 \%$ ensemble for (a) the Northern Hemisphere, and (b) the Southern Hemisphere. An overturning streamfunction measure is used determine the extent of the Hadley Cell.

Cell would conserve its axial angular momentum (Schneider and Lindzen 1977; Schneider 1977). If the zonal wind at the equator were zero then the zonal wind of the outflowing air within the Hadley Cell would be given by

$$
\bar{u}=\Omega a \frac{\sin ^{2} \phi}{\cos \phi}
$$

where $\Omega$ and $a$ are the rotation rate and radius of Earth and $\phi$ is latitude. If the near surface wind is small then (5.1) implies a very large shear and so a large meridional temperature gradient, and the requirement that the thermodynamic equation is also satisfied leads to quantitative theory for the latitudinal extent and strength of the Hadley Cell both in the annual average (Held and Hou 1980) and with seasonal variations (Lindzen and Hou 1988). The Held-Hou theory predicts that the latitudinal extent of the Hadley 
Cell, $\phi_{H}$ is given by

$$
\phi_{H}=\left(\frac{5 \Delta_{h} \theta g H}{3 a^{2} \Omega^{2} \theta_{0}}\right)^{1 / 2} \sim\left(\Delta_{h} \theta H\right)^{1 / 2}
$$

where $\Delta_{h} \theta$ is proportional to the equator-pole radiative-equilibrium potential temperature difference, $\theta_{0}$ is a constant, $H$ is the height of the outflow, $a$ is the radius of Earth and $\Omega$ its rotation rate. The dependence on height arises because the higher the outflow the weaker the ensuing temperature gradient (by thermal wind), and so the further polewards the circulation must go to for the thermodynamic budget to balance.

The contribution of this theory is that it predicts that the Hadley Cell has a finite meridional extent even in the absence of baroclinic eddies. However, the atmosphere does have baroclinic eddies and if the shear corresponding to the zonal wind in (3.1) becomes significantly baroclinically unstable then a recognizable Hadley Cell will terminate. This is the more traditional view of the general circulation as implicit in discussions by (Lorenz 1967) and others, and it is widely accepted that the Hadley Cell is influenced by baroclinic eddies. An appropriate criterion for 'significantly baroclinically unstable' is however, hard to quantify. The Eady problem has no minimum shear for instability and furthermore it neglects the beta effect which is almost certainly important at low latitudes. The Charney problem also has no minimum shear, but a small shear gives a shallow, weak instability. The two-level (Phillips) problem is somewhat unrealistic, but its critical shear is related to the condition that modes become deep in the continuously stratified problem and it does at least give a criterion that one can use in practice. The critical shear in this problem is given by

$$
U=\frac{1}{4} \beta L_{d}^{2}
$$

where $U=U_{1}-U_{2}$ is the velocity difference between the upper and lower level and $L_{d}$ is the deformation radius. We might suppose that if $\bar{u}>C U$, where $C$ is a constant, the Hadley Cell will terminate, although there are too many assumptions and approximations for the prediction to be truly quantitative. Equating (5.1) with (5.3), with $\beta=2 \Omega \cos \phi / a$ and $L_{d}=N H / f=$ $N H /(2 \Omega \sin \phi)$ leads to a critical latitude $\phi_{c}$ that, neglecting constant factors, satisfies

$$
\frac{\sin ^{4} \phi_{c}}{\cos ^{2} \phi_{c}}=\frac{N^{2} H^{2}}{\Omega^{2} a^{2}},
$$

or, with a small angle approximation,

$$
\phi_{c} \approx\left(\frac{N^{2} H^{2}}{\Omega^{2} a^{2}}\right)^{1 / 4} \sim(N H)^{1 / 2} \sim\left(H \Delta_{v} \theta\right)^{1 / 4},
$$

where $\Delta_{v} \theta$ is the difference in potential temperature between surface and tropopause, or the 'gross dry static stability'. The above scaling follows from (Held 2000) with further discussion and numerical examination by Walker and Schneider (2006) and Frierson et al. (2007). Korty and Schneider (2008) avoid the need for a specific model of baroclinic instability by suggesting that the Hadley Cell terminate when meridional eddy heat fluxes become sufficiently deep, and this occurs when the supercriticality (a particular measure of instability) reaches some critical value. If the shear is taken to be that of an angular momentum conserving Hadley Cell outflow one then obtains a relation similar to $(5.5)$.

The dependencies of Hadley cell extent on outflow height (and hence on tropopause height) given by (5.2) and (5.4) are small but by no means negligible. Suppose, for example, that the tropopause height were to increase by $4 \%$ (about $500 \mathrm{~m}$ over $12 \mathrm{~km}$ ), which might be expected from the arguments of section 3.1 for a $1^{\circ}$ temperature increase. If $\phi_{c}$ were to vary as $H^{1 / 2}$ the latitudinal extent would increase by about $2 \%$, or about $0.4^{\circ}$ latitude, similar to that found by Frierson et al. (2007) and very roughly comparable to the results of Fig. 21, although the scatter there is large. Still smaller expansion of the Hadley Cell would be expected from a quarter-power dependence. However, an examination of the results from individual models suggests that it is (5.4), not (5.2), that scales with the Hadley cell extent (Frierson et al. 2007), and that it is the static stability dependence that is dominant when climate changes, at least when the changes are large. Frierson et al interpret their results as arising from a general increase in gross static stability which reduces baroclinic instability and so pushes its onset to higher latitudes, and Kang and Lu (2012) also attribute the expansion of the Hadley Cell to an increase in subtropical static stability, in all seasons. Whether or not this interpretation is correct (that of Korty and Schneider 2008 is rather different) the subtropical static stability undoubtedly plays a role in the onset of baroclinic instability and the termination of a classical Hadley Cell. It would be useful to see how the Hadley Cell expansion correlates with changes in static stability in the CMIP5 ensemble, another topic for future work.

We also remark that the mechanism of Tandon et al. (2013) is different again; here the overturning circulation responds to a broad increase in the thermal forcing at low latitudes - such as arises in global warming but not in El Niño events, even though static stability changes the same way in both - by way of a poleward shift of the descending branch. If the increase is applied only to a narrow region around the 
tropics (as in an El Niño) then the Hadley Cell contracts. Their result seems quite robust - in their idealized GCM - and can be explained if it is assumed that the total meridional heat transport (eddy plus mean) can be parameterized diffusively. A relatively simple model of the transformed Eulerian mean circulation then predicts that the Hadley Cell will expand if the additional thermal source is sufficiently broad, and an attractive feature of their model is that it captures the difference between El Niño and global warming.

An increase in the gross dry static stability with temperature can certainly be expected if the lapse rate is moist adiabatic, and the increase will be compounded if the tropopause height itself increases. However, the subtropical static stability most likely also depends on both baroclinic eddy processes and moist effects, and although some progress has recently been made in understanding how the latent heat release modifies the static stability of eddying circulations (O'Gorman 2011), a quantitative, tractable, theory for static stability in a moist, eddying atmosphere remains elusive.

\subsection{Strength of the Hadley Cell}

A number of studies have found and/or argued that the strength of aspects of the tropical circulation will weaken with global warming (Knutson and Manabe 1995; Vecchi and Soden 2007; Held and Soden 2006; Kang et al. 2013), although there is some evidence from reanalyses that the boreal winter Hadley Cell has actually strengthened in recent decades (Mitas and Clement 2005). Using the CMIP3 ensemble Kang et al. (2013) found a weakening of the Hadley Cell, but one that was confined to the Northern Hemisphere and with more weakening in winter than in summer.

\section{Model results}

We defined Hadley Cell strength calculation as the peak value of the streamfunction over the whole pressure column within the Hadley Cell latitude bounds. Those months that were deemed undefined in the calculation of the Hadley Cell extent using the 10\% streamfunction metric were also left as undefined in the Hadley Cell strength data. We also define the winter cell to be the cell that descends in the winter hemisphere (with the summer cell being wholly contained in the summer hemisphere). Thus, the Southern Hemisphere winter cell and the Northern Hemisphere winter cell are the cells that span the equator in June-July-August and December-January-February, respectively.

In the CMIP5 collection we find a noticeable weakening in most models in both seasons, but largely confined to the Northern hemisphere (Fig. 24). The absolute value of the weakening is largest in winter but the fractional changes are larger in the summer hemisphere. However, the intermodel scatter of the change is larger than the average change, and a number of models report a strengthening. This lack of consistency in the response is consistent with the notion that multiple factors affect the strength of the Hadley Cell, as we now discuss.

\subsection{Theoretical interpretation}

A general weakening of the tropical circulation might be expected from thermodynamic and energetic arguments involving water vapour concentration and precipitation (Boer 1993; Held and Soden 2006) and reviewed by Schneider et al. (2010). In brief, unless changes in relative humidity are very large, changes in the water vapour content of the atmosphere are mainly determined by changes in the saturation vapour pressure and hence by the Clausius-Clapeyron relation, and so increase by about $7 \% \mathrm{~K}^{-1}$. However, maintaining a surface energy balance constrains the changes in evaporation and precipitation to be closer to $3 \% \mathrm{~K}^{-1}$. Thus, the overall water vapour turnover rate will decrease as surface temperature increase, possibly leading to a weakening of the atmospheric circulation, and in particular the tropical circulation - at least to the degree that the circulation is controlled by such an effect. It is however by no means clear that the dynamics of the Hadley Cell is so controlled.

The Hadley Cell may be thought of as being 'driven' by two rather distinct effects (e.g., Vallis 2006, chapter 11 ). One of them is the meridional gradient of the thermal forcing across the tropics, and the second is the divergence of the eddy momentum flux, and these both appear on the right-hand side of an elliptic equation for the overturning streamfunction (Vallis 1982). The full equation (which may be derived assuming primarily that the zonal wind is in gradient wind balance) is rather complicated, but with geostrophic scaling (which is not quantitatively accurate but leads to similar dependencies) the equation takes the simpler form

$$
f^{2} \frac{\partial^{2} \Psi}{\partial z^{2}}+N^{2} \frac{\partial^{2} \Psi}{\partial y^{2}}=f \frac{\partial M}{\partial z}+\frac{\partial Q}{\partial y},
$$

written for simplicity in Cartesian co-ordinates. Here, $M$ is the eddy momentum flux divergence (of the form $\left.\partial \overline{u^{\prime} v^{\prime}} / \partial y\right)$ and $Q$ represents both the diabatic heating, $J$, and the horizontal divergence of heat fluxes (and is of the form $J-\partial \overline{v^{\prime} b^{\prime}} / \partial y$ where $b$ is buoyancy.) It is by no means self-evident how any of these terms will change with global warming - both eddy 

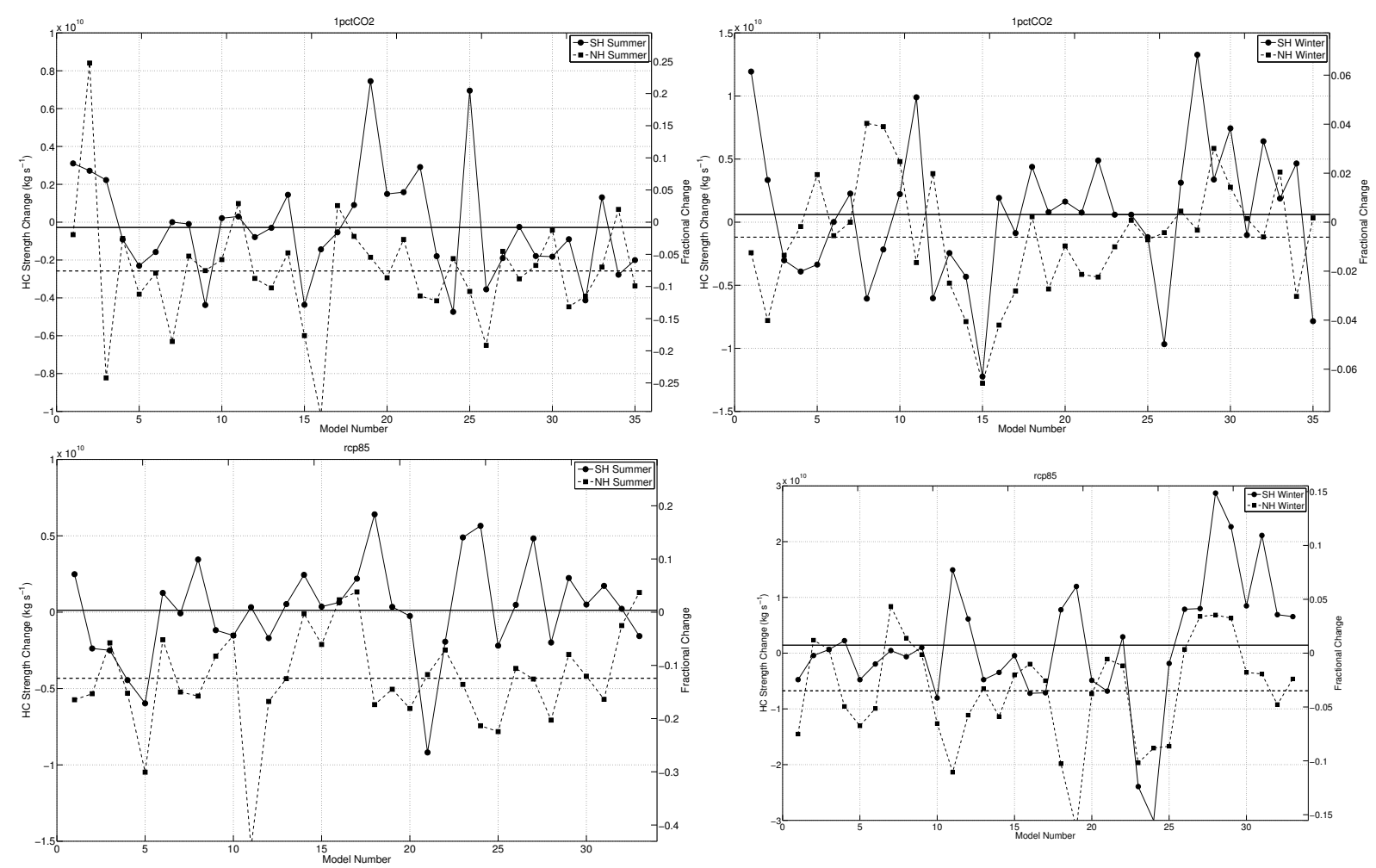

Figure 24. Changes in the strength of the Hadley Cell for models in the 1\% ensemble (top row) and RCP8.5 ensemble (bottom row) for summer and winter (left and right columns respectively). Horizontal lines show ensemble means. The fractional change is the absolute change divided my the multi-model mean for that season, and a positive change means a strengthening of the circulation in all plots.

heat and momentum fluxes terms will change if the mid-latitude eddy source (predominantly baroclinic instability) changes or if the Rossby wave breaking in the subtropics changes because of changes in the zonal wind profile. The overturning circulation will also change if the coefficients on the left-hand side of (5.6) change. Thus, if $N$ were to become larger, as for example in Frierson et al. (2007), then the Hadley Cell could weaken even if the terms on the right-hand side were to stay the same. Weakening of the Hadley Cell in winter could be due to changes in thermal forcing and in stratification, whereas in summer changes in the eddy terms may be dominant. Furthermore, there is almost no correlation between changes in Hadley Cell strength and the TCR, for either the $1 \%$ or the RCP8.5 scenario, in any season. Adding interest to the picture, Levine and Schneider (2011) find that in an idealized model the strength of the Hadley Cell can vary non-monotonically with temperature and plausible mechanisms can be proposed for these results, and Mitas and Clement (2006) argue that reanalyses of the last few decades have quite different thermodynamic balances than do models.

The problem, then, is not a shortage of possible mechanisms or results; rather, the problem lies in

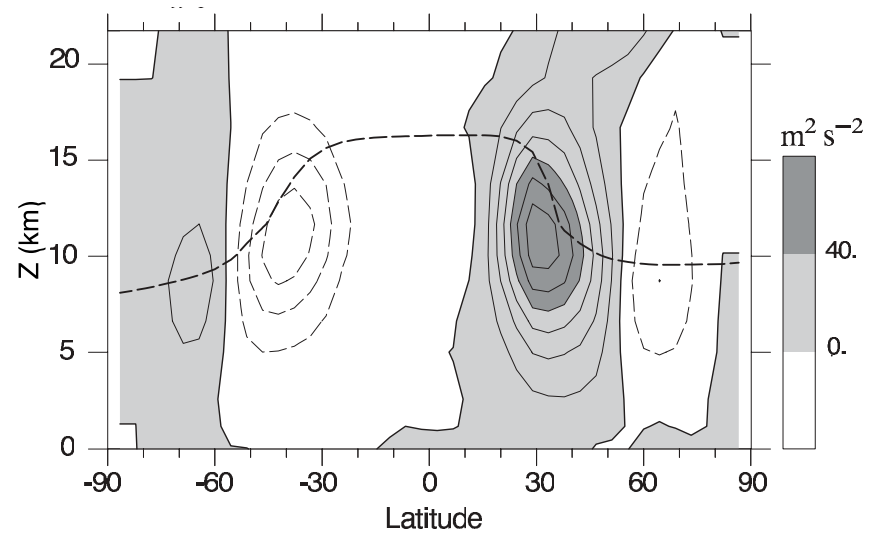

Figure 25. The eddy momentum flux, $\overline{u^{\prime} v^{\prime}}$ in northern hemisphere winter (DJF), from NCEP/NCAR reanalysis. Contour interval is $10 \mathrm{~m}^{2} \mathrm{~s}^{-2}$, positive fluxes are shaded, and the dashed near-horizontal line marks the thermal tropopause (WMO definition).

understanding which particular mechanisms actually apply, and how robust they are.

\subsection{An eddy-influenced Hadley Cell}

Both the extent and the strength of the Hadley Cell are unequivocally greatly affected by midlatitude baroclinic instability. The resulting eddy momentum 


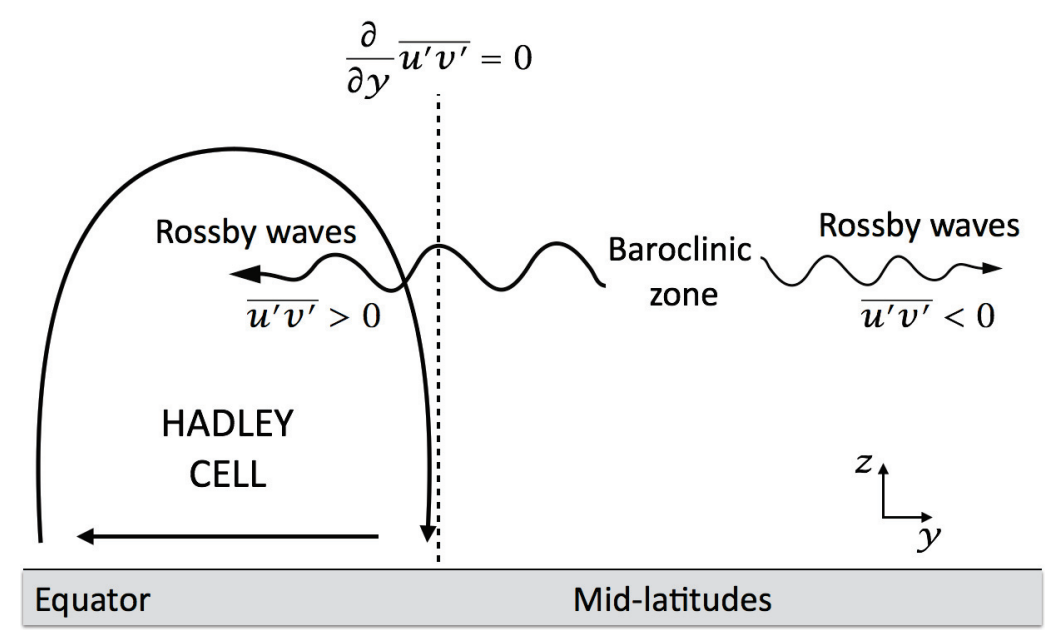

Figure 26. Schematic of an eddy-influenced Hadley Cell. Rossby waves propagating equatorward from the baroclinic zone break and dissipate in the Hadley Cell, decelerating the zonal flow, with the edge of the Hadley occurring where the eddy fluxes are a maximum. In this model, baroclinic instability need not occur until well poleward of the edge of the Hadley Cell.

and heat fluxes are non-negligible in the subtropics (Peixoto and Oort 1992) and certainly affect the strength and extent of Hadley Cell, at least in models (Schneider 2006; Walker and Schneider 2006; Vallis 2006); without baroclinic eddies the Hadley Cell would be much weaker and somewhat wider. Furthermore, we have seen that there is a positive correlation between the shift of the surface westerlies and the expansion of the Hadley Cell (Fig. 22), at least by some measures.

However, the mid-latitude eddy-driven jet is often on the verge of being distinct from the subtropical jet, even in a time average, and the instantaneous jet stream is usually well poleward of the subtropical jet. More generally, the baroclinic zone and the storm tracks are also generally regarded as being well poleward of the subtropics. These considerations suggest that the meridional extent of the Hadley Cell is not so much determined by the latitude at which it becomes baroclinically unstable but by where the Rossby waves break. Away from the surface the steady zonally-averaged zonal momentum equation is, approximately,

$$
-(f+\bar{\zeta}) \bar{v}=-\frac{1}{\cos ^{2} \phi} \frac{\partial}{\partial \phi}\left(\cos ^{2} \phi \overline{u^{\prime} v^{\prime}}\right) .
$$

Unless $\bar{\zeta}+f=0$, the edge of the Hadley Cell will occur at the maximum value of the eddy momentum fluxes, and Fig. 25 suggests that this is, at least approximately, the case in the time mean, and it is also the case on interannual timescales (Ceppi and Hartmann 2013). A plausible physical picture (sketched in Fig. 26) is that baroclinic instability occurs polewards of the Hadley Cell and Rossby waves propagate equatorward, breaking in the subtropics within the Hadley Cell and leading to the termination of the Hadley Cell somewhat polewards of that, and somewhat equatorward of the latitude where the Hadley Cell might terminate in a zonally symmetric atmosphere with no baroclinic eddies. This picture has some resemblance to the way the meridional overturning circulation of the stratosphere is driven by waves propagating from a remote source (i.e., the troposphere), although the Hadley Cell would certainly exist in the absence of eddies, and eddy heat fluxes also contribute to its budget.

Although plausible from a diagnostic point of view it may be hard to construct a scaling estimate for the Hadley Cell extent (like that of (5.5) for example) using such arguments, because the latitude of wave breaking will be determined in part by the profile of zonal wind, and so by the solution itself, and the problem is unavoidably nonlinear. (The problem then has some similarities with that of the QBO, in which the wavebreaking determines where the jet forms, which in term determines the position of the wavebreaking.) Still, in so far as the latitude of the maximum of eddy momentum fluxes does not separate substantially from the latitude of the baroclinic zone then a scaling similar to (5.5) may approximately hold.

\section{Discussion and conclusions}

The atmosphere is a nonlinear system and when trying to understand the response of its large-scale structure to greenhouse warming it can be difficult to separate causes, direct effects and feedbacks. In such a system the more complicated a chain of reasoning is the less likely it is to be robust, since the feedbacks may 
amplify, or damp, some initial perturbation with a magnitude or even a sign that depends on some illknown parameter. Furthermore, changes in circulation tend to be small: models and observations suggest that past and future shifts in such things as the meridional distribution of the surface winds are likely to be of order a degree. However, even such small shifts are important. A degree or two expansion of the subtropics could bring wholesale changes in the climate to extensive regions, and likewise a small shift in the midlatitude westerlies could significantly affect, among other things, the climate of much of Europe.

To proceed, we found it convenient to separate the effects of warming into thermodynamic/radiative effects and dynamic effects. The former can be more directly linked to changes in greenhouse-gas forcing and serve as a starting point for studies of the latter. An increase in global temperature will affect the dynamics in so far as it affects water vapour and radiative properties, with the latter effect being important not just because of the appearance of absolute temperature $\left(\sigma T^{4}\right)$ in the Stefan-Boltzmann law but because of the requirement that the outgoing infra-red radiation should approximately balance the net incoming solar radiation, and if the latter is fixed but the surface temperature increases then the vertical temperature profile must change.

An immediate effect of increasing temperature is a decrease in the moist adiabatic lapse rate, and therefore an increased static stability in regions of moist convection. The direct effect is that warming is amplified aloft at low latitudes, and with a lapse rate reduction of about $0.1 \mathrm{~K} / \mathrm{km}$ per degree a change in surface temperature of one degree would be roughly doubled in the upper tropical troposphere, broadly consistent with the results of Fig. 6. The upshot is that the upper-troposphere meridional temperature gradient is increased; in contrast there is a reduction of the low-level temperature gradient in the Northern Hemisphere associated with near-surface polar amplification.

The second robust effect of warming is an increase in the height of the tropopause. If we assume that the troposphere is the region in which the lapse rate is determined dynamically, and that the stratosphere is in near-radiative equilibrium and optically thin, then in a grey one-dimensional atmosphere on a planet in overall radiative equilibrium the temperature of the tropopause is fixed even as greenhouse gases are added. Then, if the temperature of the troposphere itself increases, and if the lapse rate is positive $(\partial T / \partial z<0)$, the tropopause must rise. Any decrease in tropospheric lapse rate with increased temperature (and as noted the moist adiabatic lapse rate decreases with increasing temperature) will only amplify this effect, with calculations suggesting (Fig. 8) that the total increase in tropopause height should be around $0.3 \mathrm{~km} / \mathrm{K}$. We further showed that the increase in tropopause height will occur even during the transient stage of global warming, and is not technically dependent on a global radiative balance. Although the above arguments make a number of assumptions that are not exactly satisfied - in particular they are global in nature - virtually every simulation in the CMIP5 archive shows the tropopause height increasing at all latitudes with global warming and at a similar rate to that predicted by the simpler arguments.

Slightly more involved radiative calculations further imply the stratosphere will cool with global warming. Interestingly, this only arises in the presence of a heating source such as ozone that causes the basic state temperature to increase. In this case, as optical depth of the stratosphere increases there is more cooling to space and so the temperature must decrease at any given level to maintain a balance with the shortwave heating.

The above thermodynamic/radiative arguments are straightforward, they do not depend sensitively on parameters, and they are supported by results from comprehensive models, factors which taken together give us confidence in them and justify us in calling them robust.

The ensuing dynamical changes in the circulation are not nearly as robust or as well understood, but it is not the case that nothing can be said. Thus, an increase in height of the tropopause coupled with an increase in static stability of the subtropics leads us to expect an expansion in the Hadley Cell, and this is seen robustly across a suite of comprehensive models, especially in the winter hemisphere. However, static stability also increases in El Nño years (when the Hadley Cell contracts) so it is certainly not the sole determining factor. Hadley Cell termination also depends on the extent to which baroclinic eddy fluxes penetrate equatorwards, and indeed there is a correlation between the the midlatitude jet shift and the expansion of the Hadley Cell. The correlation depends on the metric chosen for the Hadley Cell width, consistent with the notion that the Hadley Cell termination is eddy influenced but not solely determined by the location of baroclinic instability.

It is fair to say that we do not have a quantitative theory of baroclinic eddy fluxes, or of static stability. The two are linked in that static stability depends on the interaction of baroclinic instability with convection, and the eddy flux penetration depends on both the initial eddy strength and the profile of zonal wind in the subtropics, which affects how the waves 
break. These various considerations may preclude an a priori prediction of Hadley Cell expansion with global warming without using comprehensive models, but there is no reason at this stage to suppose that the expansion is a model artifact or a transient phenomenon.

xxx There is, on average, a weakening of the Hadley Cell largely confined to the Northern Hemisphere, with a larger absolute change in the winter cell but a larger fractional change in summer. The inter-model scatter however is larger than the mean change, and a number of models predict a strengthening of the Hadley Cell. A number of mechanisms are possible but none that are obviously compelling, especially given the large variability of model results and the the fact that observations suggest that the actual Hadley Cell might have strengthened in recent decades, behaviour that is not captured by most models.

The polewards movement of the storm tracks and the surface westerlies has a similar flavour: the movement is seen consistently across a range of models yet we do not have a single compelling, accepted theory. The simplest point of view is that the changes in thermal structure of the troposphere push the region of baroclinic instability poleward with a consequent polewards movement of the storm tracks and surface westerlies. However, without doing a detailed calculation (that is likely quite sensitive to parameters) the polewards movement of the baroclinicity cannot be predicted and other arguments related to the change in phase speed and/or size of the baroclinic eddies are equally plausible. Furthermore, stratospheric influences may, by weakening the polar vortex, lead to an equatorward shift of the mid-latitude westerlies that may counteract any delicate tropospheric mechanisms, perhaps especially in winter.

The mid-latitude surface westerlies strengthen with global warming, especially in the Southern Hemisphere. In fact in the Northern Hemisphere summer the westerlies weaken. If and how this is tied the position of the westerlies cannot be said with confidence. Understanding strength and longitudinal extent of storm tracks in a future climate may be an even more difficult problem, but one that is of great importance for regional climate. Numerical studies (O'Gorman 2010) suggest that storm-track intensity scales with the 'mean available potential energy', a quantity that increases with increasing horizontal temperature gradients and with decreasing static stability, and that also increases with latent heat release, but has no simple relation with global temperature.
It is clear that to make progress in all these issues we must look at the detailed behaviour of individual models. Also, given the potential complexity of some of these effects and simpler nature of some of the underlying causes, a way forward in understanding and predicting the changes in atmospheric circulation - and so in regional climate change - lies in the coordinated use of comprehensive models, idealized models, and physical arguments.

\section{Acknowledgements}

The authors would like to thank two anonymous reviewers for their useful, detailed comments, as well as Paolo Ceppi and Adam Scaife. The work was funded by the National Science Foundation under grant AGS1144302 , by the Royal Society, Wolfson Foundation, and by the Ministry of Science and Innovation of Spain, grant CGL2012-30641.

\section{Appendix: Analytic Approximation for Tropopause Height}

In this section we provide an approximate analytic expression for the tropopause height and show that it depends only weakly on the outgoing longwave radiation (or absolute temperature) for a given optical depth. Aside from any intrinsic value, the expression shows that the tropopause height will increase very soon after additional absorbers have been added to the atmosphere, and in particular as soon as the atmosphere has reached a new radiative-convective equilibrium and without waiting for the planet itself to come into an overall radiative equilibrium. The derivation invokes a one-dimensional radiativeequilibrium calculation in which we assume that the lapse rate, $\Gamma$, is specified up to a tropopause height $H_{T}$, beyond which the atmosphere is optically thin and in radiative equilibrium, as discussed in the main text.

Motivated by the fact that the formal solution of the radiative transfer equations, (3.1), involve the exponential factor $\exp (-\tau)$ (for example Petty 2006) and that $\tau$ itself is approximately an exponential in $z$, we write (3.1a) in the logarithmic form

$$
\frac{\mathrm{d} \log U}{\mathrm{~d} \tau}=1-\frac{B}{U}
$$

At the tropopause $U=O L R=2 B$ whereas at the ground $U=B$, and we assume that the value of $B / U$ varies linearly between these two values, so that $B / U=1-z / 2 H_{T}$. Numerical calculations (not shown) indicate that this is a good approximation in both optically thick and thin limits. Equation (6.1) becomes

$$
\frac{\mathrm{d} \log U}{\mathrm{~d} \tau}=\frac{z}{2 H_{T}}
$$


Table 2. As for table 1 but for RCP8.5.

Table 1 . Models used within the $1 \%$ ensemble, with the fields available denoted by a bullet and the names following IPCC conventions. Thus, 'ua' denotes zonal wind fields, 'uas' denotes surface zonal winds, 'va' denotes meridional winds, 'ta' denotes temperature and 'tas' denotes surface temperature. The model numbers used in the figures follow the order in the table.

\begin{tabular}{|c|c|c|c|c|c|}
\hline & ua & uas & va & ta & tas \\
\hline ACCESS1-0 & $\bullet$ & $\bullet$ & & & $\bullet$ \\
\hline ACCESS1-3 & - & $\bullet$ & & & $\bullet$ \\
\hline BNU-ESM & • & $\bullet$ & & $\bullet$ & $\bullet$ \\
\hline CCSM4 & - & & $\bullet$ & $\bullet$ & $\bullet$ \\
\hline CESM1-BGC & - & & $\bullet$ & $\bullet$ & $\bullet$ \\
\hline CESM1-CAM5 & - & & $\bullet$ & $\bullet$ & • \\
\hline CESM1-CAM5-1-FV2 & $\bullet$ & & $\bullet$ & & $\bullet$ \\
\hline CMCC-CM & $\bullet$ & $\bullet$ & $\bullet$ & $\bullet$ & $\bullet$ \\
\hline CNRM-CM5 & • & $\bullet$ & $\bullet$ & $\bullet$ & • \\
\hline CNRM-CM5-2 & $\bullet$ & $\bullet$ & $\bullet$ & $\bullet$ & $\bullet$ \\
\hline CSIRO-Mk3-6-0 & $\bullet$ & & & & $\bullet$ \\
\hline CSIRO-Mk3L-1-2 & $\bullet$ & & & & \\
\hline CanESM2 & $\bullet$ & $\bullet$ & $\bullet$ & $\bullet$ & $\bullet$ \\
\hline FGOALS-g2 & $\bullet$ & & $\bullet$ & $\bullet$ & $\bullet$ \\
\hline FGOALS-s2 & $\bullet$ & $\bullet$ & $\bullet$ & $\bullet$ & $\bullet$ \\
\hline GFDL-CM3 & $\bullet$ & $\bullet$ & & $\bullet$ & $\bullet$ \\
\hline GFDL-ESM2G & $\bullet$ & $\bullet$ & & $\bullet$ & $\bullet$ \\
\hline GFDL-ESM2M & $\bullet$ & $\bullet$ & & $\bullet$ & $\bullet$ \\
\hline GISS-E2-H & $\bullet$ & $\bullet$ & & & $\bullet$ \\
\hline GISS-E2-R & $\bullet$ & $\bullet$ & & & $\bullet$ \\
\hline HadGEM2-ES & $\bullet$ & $\bullet$ & $\bullet$ & & $\bullet$ \\
\hline IPSL-CM5A-LR & $\bullet$ & $\bullet$ & $\bullet$ & $\bullet$ & $\bullet$ \\
\hline IPSL-CM5A-MR & $\bullet$ & $\bullet$ & $\bullet$ & $\bullet$ & $\bullet$ \\
\hline IPSL-CM5B-LR & $\bullet$ & $\bullet$ & $\bullet$ & $\bullet$ & $\bullet$ \\
\hline MIROC-ESM & $\bullet$ & $\bullet$ & $\bullet$ & $\bullet$ & $\bullet$ \\
\hline MIROC5 & $\bullet$ & $\bullet$ & $\bullet$ & $\bullet$ & $\bullet$ \\
\hline MPI-ESM-LR & • & $\bullet$ & $\bullet$ & $\bullet$ & $\bullet$ \\
\hline MPI-ESM-MR & • & $\bullet$ & $\bullet$ & $\bullet$ & • \\
\hline MPI-ESM-P & - & $\bullet$ & $\bullet$ & $\bullet$ & $\bullet$ \\
\hline MRI-CGCM3 & - & $\bullet$ & $\bullet$ & $\bullet$ & $\bullet$ \\
\hline NorESM1-M & - & $\bullet$ & $\bullet$ & $\bullet$ & • \\
\hline NorESM1-ME & $\bullet$ & $\bullet$ & $\bullet$ & $\bullet$ & $\bullet$ \\
\hline bcc-csm1-1 & $\bullet$ & $\bullet$ & $\bullet$ & $\bullet$ & $\bullet$ \\
\hline bcc-csm1-1-m & $\bullet$ & $\bullet$ & $\bullet$ & • & • \\
\hline inmcm4 & $\bullet$ & $\bullet$ & & & $\bullet$ \\
\hline
\end{tabular}

\begin{tabular}{|c|c|c|c|c|c|}
\hline & ua & uas & va & ta & tas \\
\hline ACCESS1-0 & $\bullet$ & $\bullet$ & & & $\bullet$ \\
\hline ACCESS1-3 & $\bullet$ & $\bullet$ & & & $\bullet$ \\
\hline BNU-ESM & $\bullet$ & $\bullet$ & $\bullet$ & $\bullet$ & $\bullet$ \\
\hline CCSM4 & $\bullet$ & & $\bullet$ & $\bullet$ & $\bullet$ \\
\hline CESM1-BGC & $\bullet$ & & $\bullet$ & $\bullet$ & $\bullet$ \\
\hline CESM1-CAM5 & $\bullet$ & & $\bullet$ & $\bullet$ & $\bullet$ \\
\hline CESM1-CAM5-1-FV2 & $\bullet$ & & $\bullet$ & & \\
\hline CESM1-WACCM & $\bullet$ & & & & $\bullet$ \\
\hline CMCC-CESM & $\bullet$ & $\bullet$ & $\bullet$ & $\bullet$ & $\bullet$ \\
\hline CMCC-CM & $\bullet$ & $\bullet$ & $\bullet$ & $\bullet$ & $\bullet$ \\
\hline CMCC-CMS & $\bullet$ & $\bullet$ & $\bullet$ & $\bullet$ & $\bullet$ \\
\hline CNRM-CM5 & $\bullet$ & $\bullet$ & $\bullet$ & $\bullet$ & $\bullet$ \\
\hline CNRM-CM5-2 & $\bullet$ & & & & \\
\hline CSIRO-Mk3-6-0 & $\bullet$ & $\bullet$ & & & $\bullet$ \\
\hline CanESM2 & $\bullet$ & $\bullet$ & $\bullet$ & $\bullet$ & $\bullet$ \\
\hline EC-EARTH & $\bullet$ & $\bullet$ & & $\bullet$ & $\bullet$ \\
\hline FGOALS-g2 & $\bullet$ & & & & $\bullet$ \\
\hline FGOALS-s2 & & & & & $\bullet$ \\
\hline FIO-ESM & $\bullet$ & & & & $\bullet$ \\
\hline GFDL-CM3 & $\bullet$ & $\bullet$ & $\bullet$ & $\bullet$ & $\bullet$ \\
\hline GFDL-ESM2G & $\bullet$ & $\bullet$ & $\bullet$ & $\bullet$ & $\bullet$ \\
\hline GFDL-ESM2M & $\bullet$ & $\bullet$ & $\bullet$ & $\bullet$ & $\bullet$ \\
\hline GISS-E2-H & $\bullet$ & $\bullet$ & $\bullet$ & & $\bullet$ \\
\hline GISS-E2-H-CC & $\bullet$ & $\bullet$ & $\bullet$ & & $\bullet$ \\
\hline GISS-E2-R & $\bullet$ & $\bullet$ & $\bullet$ & & $\bullet$ \\
\hline GISS-E2-R-CC & $\bullet$ & $\bullet$ & $\bullet$ & & $\bullet$ \\
\hline HadGEM2-AO & $\bullet$ & $\bullet$ & & & $\bullet$ \\
\hline HadGEM2-CC & $\bullet$ & $\bullet$ & $\bullet$ & $\bullet$ & $\bullet$ \\
\hline HadGEM2-ES & $\bullet$ & $\bullet$ & $\bullet$ & $\bullet$ & $\bullet$ \\
\hline IPSL-CM5A-LR & $\bullet$ & $\bullet$ & $\bullet$ & $\bullet$ & $\bullet$ \\
\hline IPSL-CM5A-MR & $\bullet$ & $\bullet$ & $\bullet$ & $\bullet$ & $\bullet$ \\
\hline IPSL-CM5B-LR & $\bullet$ & $\bullet$ & $\bullet$ & $\bullet$ & $\bullet$ \\
\hline MIROC-ESM & $\bullet$ & $\bullet$ & $\bullet$ & $\bullet$ & $\bullet$ \\
\hline MIROC-ESM-CHEM & $\bullet$ & $\bullet$ & $\bullet$ & $\bullet$ & $\bullet$ \\
\hline MIROC5 & $\bullet$ & $\bullet$ & $\bullet$ & $\bullet$ & $\bullet$ \\
\hline MPI-ESM-LR & $\bullet$ & $\bullet$ & $\bullet$ & $\bullet$ & $\bullet$ \\
\hline MPI-ESM-MR & $\bullet$ & $\bullet$ & $\bullet$ & $\bullet$ & $\bullet$ \\
\hline MRI-CGCM3 & $\bullet$ & $\bullet$ & $\bullet$ & $\bullet$ & $\bullet$ \\
\hline MRI-ESM1 & $\bullet$ & $\bullet$ & $\bullet$ & $\bullet$ & \\
\hline NorESM1-M & $\bullet$ & $\bullet$ & $\bullet$ & $\bullet$ & $\bullet$ \\
\hline bCC-CSM1-1 & $\bullet$ & $\bullet$ & $\bullet$ & $\bullet$ & $\bullet$ \\
\hline InMMTM1-1-m & $\bullet$ & $\bullet$ & $\bullet$ & $\bullet$ & $\bullet$ \\
\hline & $\bullet$ & $\bullet$ & & & $\bullet$ \\
\hline
\end{tabular}



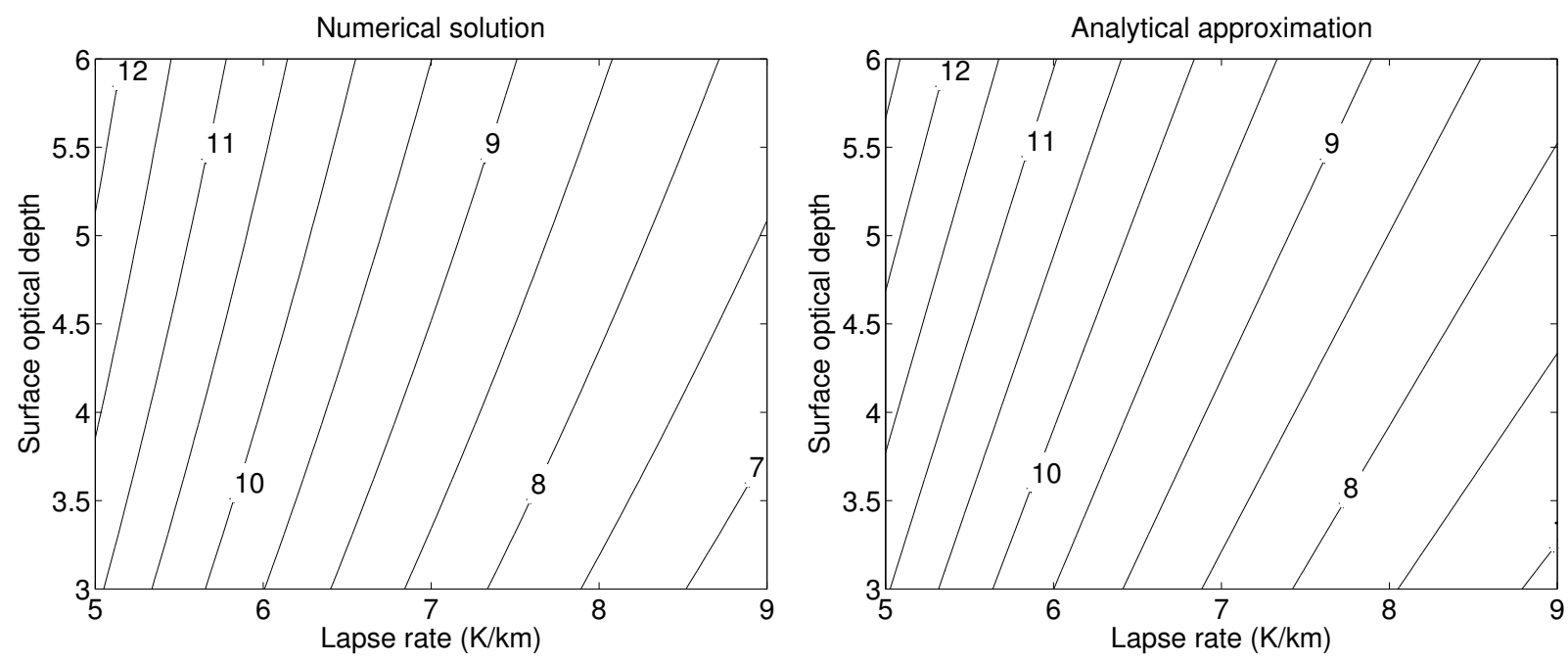

Figure 27. Contour plots of numerical solution and analytic approximation of the radiative-convective equations for the height of the tropopause as a function of lapse rate and optical depth.

or, with $\tau(z)=\tau_{s} \exp \left(-z / H_{a}\right)$,

$$
\frac{\mathrm{d} \log U}{\mathrm{~d} z}=-\frac{z}{2 H_{T} H_{a}} \tau_{s} \exp \left(-z / H_{a}\right) .
$$

Integrating this expression by parts yields a value of the upwelling radiation at the tropopause $U\left(H_{T}\right)$, namely

$\log \left(\frac{U\left(H_{T}\right)}{U(0)}\right)=-\frac{\tau_{s}}{2 H_{T}} \int_{0}^{H_{T}} \exp \left(-z / H_{a}\right) \mathrm{d} z \approx-\frac{\tau_{s} H_{a}}{2 H_{T}}$,

where $U\left(H_{T}\right)=2 \sigma T_{T}^{4}$ and $U(0)=\sigma T_{0}^{4}$ and $T_{0}=T_{H}+$ $\Gamma H_{T}$ and we assumed that $H_{T}>>H_{a}$. If $U\left(H_{T}\right)$ is taken as known then (6.4) is a closed equation for the tropopause height. Essentially, (6.4) enforces the condition that a temperature profile of a constant lapse rate up to some height $H_{T}$ produces the correct outgoing longwave radiation.

One way to evaluate (6.4) is to expand the logarithm on the left-hand side, giving

$$
\begin{aligned}
\log \left(\frac{2 \sigma T_{T}^{4}}{\sigma T_{0}^{4}}\right) & =\log 2+4 \log \frac{T_{T}}{T_{0}} \\
& =\log 2+4 \log \left(\frac{T_{T}}{T_{T}+\Gamma H_{T}}\right) \\
& \approx \log 2-\frac{4 \Gamma H_{T}}{T_{T}}
\end{aligned}
$$

Using (6.5), (6.4) becomes

$$
\log 2-\frac{4 \Gamma H_{T}}{T_{T}}=-\frac{\tau_{s} H_{a}}{2 H_{T}}
$$

or

$$
8 \Gamma H_{T}^{2}-\mathrm{C} H_{T} T_{T}-\tau_{s} H_{a} T_{T}=0 .
$$

where $\mathrm{C}=2 \log 2 \approx 1.38$. For Earth's atmosphere all three terms in (6.7) are of similar size.
A slightly different way to proceed is to note that in hydrostatic balance and with a constant lapse rate the tropopause and surface temperatures are related by

$$
\frac{T_{T}}{T_{0}}=\left(\frac{p_{T}}{p_{0}}\right)^{R \Gamma / g},
$$

where $p_{T}$ and $p_{0}$ are the tropopause and surface pressures, respectively. It follows that

$$
\log \left(\frac{T_{T}}{T_{0}}\right)=-\frac{R \Gamma}{g} \frac{H_{T}}{H_{s}},
$$

assuming that the pressure falls off exponentially with scale height $H_{s}$. Instead of (6.5) we then have

$$
\log \left(\frac{2 \sigma T_{T}^{4}}{\sigma T_{0}^{4}}\right) \approx \log 2-\frac{4 R \Gamma}{g} \frac{H_{T}}{H_{s}},
$$

and (6.7) is replaced by an equation of the same form, but with $T_{T}$ replaced by $\hat{T}$ where $\hat{T}=g H_{s} / R$.

Written using $\hat{T}$, the solution of (6.7) is

$$
H_{T}=\frac{1}{16 \Gamma}\left(\mathrm{C} \hat{T}+\sqrt{\mathrm{C}^{2} \hat{T}^{2}+32 \Gamma \tau_{s} H_{a} \hat{T}}\right)
$$

and the solution is contoured in Fig. 27 for a given $\hat{T}$, along with the exact numerical solution obtained iteratively as described in the main text. The two solutions are evidently very similar.

From (6.11), and taking $\mathrm{C}^{2} \approx 2$, we can identify the optically thin and thick limits,

Thick: $\quad \tau_{s} H_{a} \gg \frac{\hat{T}}{16 \Gamma}$ whence $H_{T} \approx \sqrt{\frac{\hat{T} \tau_{s} H_{a}}{8 \Gamma}}$

Thin: $\quad \tau_{s} H_{a} \ll \frac{\hat{T}}{16 \Gamma}$ whence $H_{T} \approx \frac{\mathrm{C} \hat{T}}{8 \Gamma}$.

Prepared using ajrms4.cls 
For any conceivable global warming, fractional changes in optical depth are much larger than fractional changes in temperature and from (6.11) or (6.12) we see that the tropopause height is relatively weakly dependent on the temperature itself. Moreover, as the analytical expression (6.7) illustrates, the incoming solar radiation primarily affects tropopause height through its effect on the mean temperature/scale height. Thus, and as Fig. 9 illustrates, the tropopause height will adjust close to its final equilibrium value during the initial atmospheric adjustment to the greenhouse gas increase even if the planet as a whole is not in radiative balance, presuming that atmospheric temperatures warm modestly during the subsequent adjustment to final equilibrium and no significant additional feedbacks occur.

\section{References}

Allen RJ, Sherwood SC, Norris JR, Zender CS. 2012. Recent Northern Hemisphere tropical expansion primarily driven by black carbon and tropospheric ozone. Nature 485(7398): 350-354.

Archer CL, Caldeira K. 2008. Historical trends in the jet streams. Geophysical Research Letters 35(8).

Barnes EA, Polvani LM. 2013. Response of the midlatitude jets and of their variability to increased greenhouse gases in the CMIP5 models. J. Climate 26: 7117-7135.

Bender FAM, Ramanathan V, Tselioudis G. 2011. Changes in extratropical storm track cloudiness 1983-2008: observational support for a poleward shift. Climate Dyn. 27: 1-17, doi:10.1007/ s00382-011-1065-6.

Bintanja R, Graversen R, Hazeleger W. 2011. Arctic winter warming amplified by the thermal inversion and consequent low infrared cooling to space. Nature Geoscience 4(11): 758-761.

Birner T. 2010. Residual circulation and tropopause structure. $J$. Atmos. Sci. 67: 2582-2600.

Boer G. 1993. Climate change and the regulation of the surface moisture and energy budgets. Climate Dyn. 8(5): 225-239.

Butchart N, Coauthors. 2006. Simulations of anthropogenic change in the strength of the Brewer-Dobson circulation. Climate Dyn. 27: 727-741.

Butler AH, Thompson DWJ, Heikes R. 2010. The steady-state atmospheric circulation response to climate change-like thermal forcings in a simple general circulation model. J. Climate 23: 34743496.

Caballero R, Langen PL. 2005. The dynamic range of poleward energy transport in an atmospheric general circulation model. Geophys. Res. Lett. 32: L02 705, doi:10.1029/2004GL021 581, doi:\{doi:10. 1029/2004GL021581\}.

Ceppi P, Hartmann DL. 2013. On the speed of the eddy-driven jet and the width of the Hadley Cell in the Southern Hemisphere. J. Climate 26(10).

Ceppi P, Hwang YT, Frierson DM, Hartmann DL. 2012. Southern Hemisphere jet latitude biases in CMIP5 models linked to shortwave cloud forcing. Geophys. Res. Lett. 39(19).

Chen G, Held IM. 2007. Phase speed spectra and the recent poleward shift of southern hemisphere surface westerlies. Geophys. Res. Lett. 34: L21 805.

Chen G, Lu J, Frierson DMW. 2008. Phase speed spectra and the latitude of surface westerlies: Interannual variability and global warming trend. Journal of Climate 21(22): 5942-5959.

Chou C, Chen CA, Neelin J, Tu JY. 2009. Evaluating the 'rich-get-richer' mechanism in tropical precipitation change under global warming. J. Climate 22(8): 1982-2005.
Frierson DMW, Lu J, Chen G. 2007. Width of the Hadley cell in simple and comprehensive general circulation models. Geophys. Res. Lett. 34: L18 804, doi:10.1029/2007GL031115.

Goody R. 1964. Atmospheric radiation. Clarendon Press: Oxford.

Grise KM, Polvani LM. 2014. Is climate sensitivity related to dynamical sensitivity? a Southern Hemisphere perspective. Geophys. Res. Lett. 41: 534-537, doi:10.1002/2013GL058466.

Hall NMJ, Hoskins BL, Valdes PJ, Senior CA. 1994. Storm tracks in a high-resolution GCM with doubled carbon dioxide. Quart. J. Roy. Meteor. Soc. 120: 1209-1230.

Held IM. 1982. On the height of the tropopause and the static stability of the troposphere. J. Atmos. Sci. 39: 412-417.

Held IM. 2000. The general circulation of the atmosphere. In: Woods Hole Program in Geophysical Fluid Dynamics. p. 66.

Held IM, Hou AY. 1980. Nonlinear axially symmetric circulations in a nearly inviscid atmosphere. J. Atmos. Sci. 37: 515-533.

Held IM, Soden B. 2006. Robust responses of the hydrological cycle to global warming. J. Climate 19: 5686-5699.

Hu Y, Fu Q. 2007. Observed poleward expansion of the hadley circulation since 1979. Atmos. Chem. Phys. 7: 5229-5236.

Ingram W. 2010. A very simple model for the water vapour feedback on climate change. Quart. J. Roy. Meteor. Soc. 136(646): 30-40.

Joshi M, Gregory J, Webb M, DMH S, TC J. 2008. Mechanisms for the land-sea warming contrast exhibited by simulations of climate change. Climate Dyn. 30: 455-465.

Kamae Y, Watanabe M, Kimoto M, Shiogama H. 2014. Summertime land-sea thermal contrast and atmospheric circulation over East Asia in a warming climate - Part I: Past changes and future projections. Climate Dyn. : 1-16.

Kang SM, Deser C, Polvani LM. 2013. Uncertainty in climate change projections of the Hadley Circulation: the role of internal variability. J. Climate 26(19).

Kang SM, Lu J. 2012. Expansion of the Hadley Cell under global warming: Winter versus summer. J. Climate 25(24).

Kang SM, Polvani LM. 2011. The interannual relationship between the latitude of the eddy-driven jet and the edge of the Hadley Cell. Journal of Climate 24(2).

Karpechko AY, Manzini E. 2012. Stratospheric influence on tropospheric climate change in the Northern Hemisphere. J. Geophys. Res. (Atmospheres) 117(D5): D05 133, doi:10.1029/2011JD017036.

Kidston J, Gerber E. 2010. Intermodel variability of the poleward shift of the austral jet stream in the CMIP3 integrations linked to biases in 20th century climatology. Geophys. Res. Lett. 37(9).

Kidston J, Vallis GK. 2012. The relationship between the speed and latitude of the eddy-driven jet in a stirred barotropic model. J. Atmos. Sci. 69: 3251-3263, doi:http://dx.doi.org/10. 1175/JAS-D-11-0300.1.

Kidston J, Vallis GK, Dean SM, Renwick JA. 2011. Can the increase in the eddy length scale under global warming cause the poleward shift of the jet streams? J. Climate 24: 3764-3780, doi:http://dx. doi.org/10.1175/2010JCLI3738.1.

Knutson TR, Manabe S. 1995. Time-mean response over the tropical pacific to increased $\mathrm{c} 02$ in a coupled ocean-atmosphere model. Journal of Climate 8(9): 2181-2199.

Knutti R, Sedlacek J. 2012. Robustness and uncertainties in the new CMIP5 climate model projections. Nature Clim. Change 3: 369-373, doi:10.1038/nclimate1716.

Korty RL, Schneider T. 2008. Extent of the Hadley circulation in dry atmospheres. Geophys. Res. Lett. 35: L23 803, doi:10.1029/ 2008 GL035847.

Levine XJ, Schneider T. 2011. Response of the Hadley circulation to climate change in an aquaplanet GCM coupled to a simple representation of ocean heat transport. J. Atmos. Sci. 68(4): 769783.

Lindzen RS, Hou AY. 1988. Hadley circulation for zonally averaged heating centered off the equator. J. Atmos. Sci. 45: 2416-2427.

Loeb NG, Lyman JM, Johnson GC, Allan RP, Doelling DR, Wong T, Soden BJ, Stephens GL. 2012. Observed changes in top-of-theatmosphere radiation and upper-ocean heating consistent within uncertainty. Nature Geoscience 5(2): 110-113. 
Lorenz D. 2014. Understanding mid-latitude jet variability and change using rossby wave chromatography: Poleward shifted jets in response to external forcing. J. Atmos. Sci. In press.

Lorenz DJ, DeWeaver ET. 2007. Tropopause height and zonal wind response to global warming in the IPCC scenario integrations. $J$. Geophys. Res. 112: D10 119, doi:10.1029/2006JD008087.

Lorenz EN. 1967. The nature and the theory of the general circulation of the atmosphere, WMO Publications, vol. 218. World Meteorological Organization.

Lu J, Chen G, Frierson DM. 2010. The position of the midlatitude storm track and eddy-driven westerlies in aquaplanet AGCMs. $J$. Atmos. Sci. 67: 3984-4000, doi:10.1175/2010JAS3477.1.

Lu J, Chen G, Frierson DMW. 2008. Response of the zonal mean atmospheric circulation to El Niño versus global warming. $J$. Climate 21(22): 5835-5851.

Lu J, Vecchi GA, Reichler T. 2007. Expansion of the Hadley cell under global warming. Geophys. Res. Lett. 34: L06 805, doi:10.1029/ 2006 GL028443.

Lunkeit F, Fraedrich K, Bauer SE. 1998. Storm tracks in a warmer climate: sensitivity studies with a simplified global circulation model. Climate Dyn. 14: 813-826.

Manabe S, Wetherald RT. 1967. Thermal equilibrium of the atmosphere with a given distribution of relative humidity. J. Atmos. Sci. 24: 241-259.

Manabe S, Wetherald RT. 1980. On the distribution of climate change resulting from an increase in $\mathrm{CO}_{2}$ content of the atmosphere. $J$. Atmos. Sci. 37: 99-118.

Meehl G, Stocker T, Collins W, Friedlingstein P, Gaye A, Gregory J, Kitoh A, Knutti R, Murphy J, Noda A, Raper S, Watterson I, Weaver A, Zhao ZC. 2007. Observations: Global climate projections. In: IPCC, 2007: Climate Change 2007: The Physical Science Basis. Contribution of Working Group I to the Fourth Assessment Report of the Intergovernmental Panel on Climate Change, Solomon S, Qin D, Manning M, Chen Z, Marquis M, Averyt K, Tignor M, Miller H (eds), Cambridge University Press: Cambridge and New York, pp. 747-846.

Meinshausen M, Smith SJ, Calvin K, Daniel JS, Kainuma MLT, Lamarque JF, Matsumoto K, Montzka SA, Raper SCB, Riahi K, Thomson A, Velders GJM, van Vuuren DP. 2011. The RCP greenhouse gas concentrations and their extensions from 1765 to 2300. Climate Change 2011: 213-241, doi:10.1007/ s10584-011-0156-z.

Mitas CM, Clement A. 2005. Has the Hadley cell been strengthening in recent decades? Geophysical Research Letters 32(3): L03 809, doi: $10.1029 / 2004 G L 021765$.

Mitas CM, Clement A. 2006. Recent behavior of the Hadley cell and tropical thermodynamics in climate models and reanalyses. Geophys. Res. Lett. 33(1).

O'Gorman PA. 2010. Understanding the varied response of the extratropical storm track to climate change. Proc. Nat. Acad. Sci. 107: 19 176-19 180, doi:www.pnas.org/cg/doi/10.1073/pnas. 1011547107.

O'Gorman PA. 2011. The effective static stability experienced by eddies in a moist atmosphere. J. Atmos. Sci. 68(1).

Oman L, Waugh DW, Pawson S, Stolarski RS, Newman PA. 2009. On the influence of anthropogenic forcings on changes in the stratospheric mean age. J. Geophys. Res. 114: D03 105, doi:10. 1029/2008JD010378.

Pavan V. 1995. Sensitivity of a mulit-layer quasi-geostrophic $\beta$ channel to the vertical structure of the equilibrium meridional temperature gradient. Quart. J. Roy. Meteor. Soc. 122: 55-72.

Peixoto JP, Oort AH. 1992. Physics of climate. American Institute of Physics.

Petty GW. 2006. A first course in atmospheric radiation. Sundog Publishing: Madison, Wisc.

Polvani L, Waugh D, Correa JP, Son SW. 2011. Stratospheric ozone depletion: The main driver of 20th century atmospheric circulation changes in the Southern Hemisphere. J. Climate 24: 795-812.

Polvani LM, Kushner PJ. 2002. Tropospheric response to stratospheric perturbations in a relatively simple general circulation model. Geophys. Res. Lett. 29(7): 10.1029/2001GL014 284.
Ramaswamy V, Chanin ML, Angell J, Barnett J, Gaffen D, Gelman M, Keckhut P, Koshelkov Y, Labitzke K, Lin JJ, et al. 2001. Stratospheric temperature trends: Observations and model simulations. Reviews of Geophysics 39(1): 71-122.

Santer BD, Thorne P, Haimberger L, Taylor K, Wigley T, Lanzante J, Solomon S, Free M, Gleckler P, Jones P, et al. 2008. Consistency of modelled and observed temperature trends in the tropical troposphere. International Journal of Climatology 28(13): 17031722.

Santer BD, Wehner MF, Wigley TML, Sausen R, Meehl GA, Taylor KE, Ammann C, Arblaster J, Washington WM, Boyle JS, Bruggemann W. 2003. Contributions of anthropogenic and natural forcing to recent tropopause height changes. Science 301: 479-483.

Scaife AA, Spangehl T, Fereday DR, Cubasch U, Langematz U, Akiyoshi H, Bekki S, Braesicke P, Butchart N, Chipperfield MP, Gettelman A, Hardiman SC, Michou M, Rozanov E, Shepherd TG. 2012. Climate change projections and stratosphere-troposphere interaction. Clim. Dyn. 28: 2089-2097, doi:10.1007/s00382-011-1080-7.

Schneider EK. 1977. Axially symmetric steady-state models of the basic state for instability and climate studies. Part II: nonlinear calculations. J. Atmos. Sci. 34: 280-297.

Schneider EK, Lindzen RS. 1977. Axially symmetric steady-state models of the basic state for instability and climate studies. Part I: linearized calculations. J. Atmos. Sci. 34: 263-279.

Schneider T. 2006. The general circulation of the atmosphere. Annu. Rev. Earth Planet. Sci. 34: 1-28, doi:1056-8700/97/0610-00.

Schneider T, O'Gorman PA, Levine XJ. 2010. Water vapor and the dynamics of climate changes. Rev. Geophys. 48: RG3001, doi: 8755-1209/10/2009RG000302.

Screen JA, Simmonds I. 2010. The central role of diminshing sea ice in recent Arctic temperature amplification. Nature 464: 1550-1568.

Seidel DJ, Fu Q, Randel WJ, Reichler TJ. 2008. Widening of the tropical belt in a changing climate. Nature Geosci. 1: 21-24.

Seidel DJ, Randel WJ. 2007. Recent widening of the tropical belt: Evidence from tropopause observations. J. Geophys. Res. 112: D20 113, doi:10.1029/2007JD008861.

Shepherd TG, McLandress C. 2011. A robust mechanism for strengthening of the Brewer-Dobson circulation in response to climate change: Critical-layer control of subtropical wave breaking. J. Atmos. Sci. 68: 784-797, doi:10.1175/2010JAS3608.1.

Shine KP, Bourqui M, Forster PdF, Hare S, Langematz U, Braesicke P, Grewe V, Ponater M, Schnadt C, Smith C, et al. 2003. A comparison of model-simulated trends in stratospheric temperatures. Quarterly Journal of the Royal Meteorological Society 129(590): 15651588.

Singh MS, O'Gorman PA. 2012. Upward shift of the atmospheric general circulation under global warming: Theory and simulations. J. Climate 25: 8259-8276.

Sobel AH, Nilsson J, Polvani L. 2001. The weak temperature gradient approximation and balanced tropical moisture waves. J. Atmos. Sci. 58: 3650-3665.

Solman SA, Orlanski I. 2014. Poleward shift and change of frontal activity in the Southern Hemisphere over the last 40 years. J. Atmos. Sci. 71: 539-552, doi:10.1175/JAS-D-13-0105.1.

Stephens GL, Li J, Wild M, Clayson CA, Loeb N, Kato S, L’Ecuyer T, Stackhouse Jr PW, Lebsock M, Andrews T. 2012. An update on Earth's energy balance in light of the latest global observations. Nature Geoscience 5(10): 691-696.

Sutton RT, Dong BW, Gregory JM. 2007. Land-sea warming ratio in response to climate change: IPCC AR4 model results and comparison with observations. Geophys. Res. Lett. 34: L02 701, doi: 10.1029/2006GL028164.

Tandon NF, Gerber EP, Sobel AH, Polvani LM. 2013. Understanding Hadley cell expansion versus contraction: insights from simplified models and implications for recent observations. J. Climate 26: 4304-4321, doi:10.1175/JCLI-D-12-00598.1.

Thompson DW, Solomon S. 2002. Interpretation of recent Southern Hemisphere climate change. Science 296(5569): 895-899.

Thuburn J, Craig GC. 2000. Stratospheric influence on tropopause height: the radiative constraint. J. Atmos. Sci. 57: 17-28. 
Vallis GK. 1982. A statistical dynamical climate model with a simple hydrology cycle. Tellus 34: 211-227.

Vallis GK. 2006. Atmospheric and oceanic fluid dynamics. Cambridge University Press: Cambridge, U.K.

Vecchi GA, Soden BJ. 2007. Global warming and the weakening of the tropical circulation. Journal of Climate 20(17): 4316-4340.

Walker CC, Schneider T. 2006. Eddy influences on Hadley circulations: Simulations with an idealized GCM. J. Atmos. Sci. 63: 3333-3350.

Williams GP. 2006. Circulation sensitivity to tropopause height. $J$. Atmos. Sci. 63: 1954-1961.
Winton M. 2006. Amplified Arctic climate change: What does surface albedo feedback have to do with it? Geophys. Res. Lett. 33: L03 701, doi:10.1029/2005GL025244.

Wu Y, Ting M, Seager R, Huang HP, Cane MA. 2011. Changes in storm tracks and energy transports in a warmer climate simulated by the GFDL CM2.1 model. Clim. Dyn. 37: 53-72, doi:10.1007/ s00382-010-0776-4.

Yin JH. 2005. A consistent poleward shift of the storm tracks in simulations of 21st century climate. Geophys. Res. Lett. 32: L18 701, doi:10.1029/2005GL023684.

Zurita-Gotor P, Vallis GK. 2011. Dynamics of mid-latitude tropopause height in an idealized model. J. Atmos. Sci. 68: 823-838. 